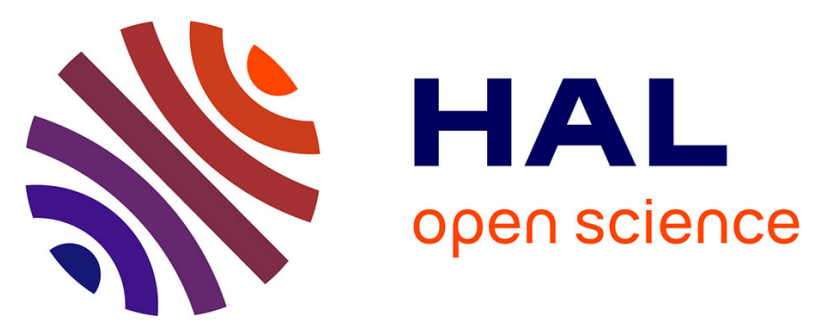

\title{
Martian polar and circum-polar sulfate-bearing deposits: Sublimation tills derived from the north polar cap
}

Marion Massé, Olivier Bourgeois, Stéphane Le Mouélic, Charles Verpoorter, Laetitia Le Deit, Jean-Pierre Bibring

\section{- To cite this version:}

Marion Massé, Olivier Bourgeois, Stéphane Le Mouélic, Charles Verpoorter, Laetitia Le Deit, et al.. Martian polar and circum-polar sulfate-bearing deposits: Sublimation tills derived from the north polar cap. Icarus, 2010, 209 (2), pp.434-451. 10.1016/j.icarus.2010.04.017 . hal-00676210

\section{HAL Id: hal-00676210 https://hal.science/hal-00676210}

Submitted on 4 Mar 2012

HAL is a multi-disciplinary open access archive for the deposit and dissemination of scientific research documents, whether they are published or not. The documents may come from teaching and research institutions in France or abroad, or from public or private research centers.
L'archive ouverte pluridisciplinaire HAL, est destinée au dépôt et à la diffusion de documents scientifiques de niveau recherche, publiés ou non, émanant des établissements d'enseignement et de recherche français ou étrangers, des laboratoires publics ou privés. 


\section{Accepted Manuscript}

Martian polar and circum-polar sulfate-bearing deposits: Sublimation tills derived from the north polar cap

M. Massé, O. Bourgeois, S. Le Mouélic, C. Verpoorter, L. Le Deit, J.P. Bibring

PII:

S0019-1035(10)00174-0

DOI:

10.1016/j.icarus.2010.04.017

Reference:

YICAR 9414

To appear in:

Icarus

Received Date: $\quad 22$ January 2010

Revised Date: $\quad 21$ April 2010

Accepted Date: $\quad 21$ April 2010

Please cite this article as: Massé, M., Bourgeois, O., Le Mouélic, S., Verpoorter, C., Le Deit, L., Bibring, J.P., Martian polar and circum-polar sulfate-bearing deposits: Sublimation tills derived from the north polar cap, Icarus (2010), doi: 10.1016/j.icarus.2010.04.017

This is a PDF file of an unedited manuscript that has been accepted for publication. As a service to our customers we are providing this early version of the manuscript. The manuscript will undergo copyediting, typesetting, and review of the resulting proof before it is published in its final form. Please note that during the production process errors may be discovered which could affect the content, and all legal disclaimers that apply to the journal pertain. 
MARTIAN POLAR AND CIRCUM-POLAR SULFATE-BEARING DEPOSITS: SUBLIMATION TILLS DERIVED FROM THE NORTH POLAR CAP

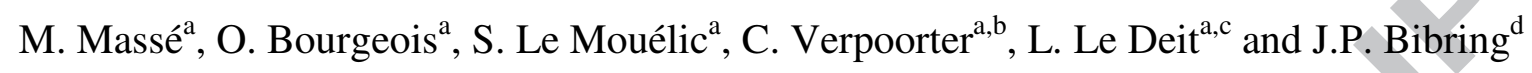

${ }^{a}$ Laboratoire de Planétologie et Géodynamique, UMR 6112, CNRS, Université de Nantes, 2

9

10
chemin de la Houssinière, BP 92205, 44322 Nantes Cedex 3,( France).

(1)

12

(1)

b Laboratoire d'Océanologie et de Géosciences, UMR LOG 8187, 32 avenue Foch, 62930

23 Number of pages: 48

24 Number of figures: 13

Wimereux, (France).

Charles.Verpoorter@univ-littoral.fr

${ }^{\mathrm{c}}$ Institute of Planetary Research, German Aerospace Center (DLR), Rutherfordstr.2, 12489

Berlin, (Germany).

Laetitia.LeDeit@dlr.de

'Institut d'Astrophysique Spatiale, Universite' Paris XI, Orsay, (France).

jean-pierre.bibring@ias.u-psud.fr 


\section{Proposed Running Head:}

26 Origin of Martian circum-polar gypsum bearing deposits

30 Please send Editorial Correspondence to:

32 Marion Massé

33 Laboratoire de Planétologie et Géodynamique,

34 UMR 6112, CNRS, Université de Nantes,

352 chemin de la Houssinière, BP 92205,

3644322 Nantes Cedex 3, France

38 Email: marion.masse@univ-nantes.fr

39 Phone: $+(0) 332.51 .12 .54 .67$

40 


\section{Abstract}

Previous spectroscopic studies have shown the presence of hydrated minerals in various kinds

51 of sedimentary accumulations covering and encircling the Martian North Polar Cap. More

52 specifically, gypsum, a hydrated calcium sulfate, has been detected on Olympia Planum, a

53 restricted part of the Circumpolar Dune Field. To further constrain the geographical distribution

54 and the process of formation and accumulation of these hydrated minerals, we performed an

55 integrated morphological, structural and compositional analysis of a key area where hydrated

56 minerals were detected and where the main polar landforms are present. By the development of a

57 spectral processing method based on spectral derivation and by the acquisition of laboratory

58 spectra of gypsum-ice mixtures we find that gypsum-bearing sediment is not restricted to the

59 Olympia Planum dunes but is also present in all kinds of superficial sediment covering the

60 surface of the North Polar Cap and the Circumpolar Dune Field. Spectral signatures consistent

61 with perchlorates are also detected on these deposits. The interpretation of landforms reveals that

62 this gypsum-bearing sediment was released from the ice cap by sublimation. We thus infer that

63 gypsum crystals that are now present in the Circum-Polar Dune Field derive from the interior of

64 the North Polar Cap. Gypsum crystals that were initially trapped in the ice cap have been released

65 by sublimation of the ice and have accumulated in the form of ablation tills at the surface of the

66 ice cap. These gypsum-bearing sublimation tills are reworked by winds and are transported

67 towards the Circum-Polar Dune Field. Comparison with sulfates found in terrestrial glaciers

68 suggests that gypsum crystals in the Martian North Polar Cap have formed by weathering of dust

69 particles, either in the atmosphere prior to their deposition during the formation of the ice cap,

70 and/or in the ice cap after their deposition.

71 Keywords: Mars, polar caps; Mars, polar geology; mineralogy; Ices, IR Spectroscopy; Mars,

72 surface. 


\section{Introduction}

Various kinds of sulfates have been discovered in several regions of Mars, both from in-situ

75 ground observations by the Spirit and Opportunity rovers and from orbital observations by the

OMEGA and CRISM imaging spectrometers. In equatorial and mid-latitude regions, $\mathrm{Mg}-, \mathrm{Fe}-$

and Ca-sulfates have been detected in light toned layered deposits and in soils [e.g. Christensen et

al., 2004; Gendrin et al., 2005; Arvidson et al., 2006; Squyres et al., 2006; Le Deit et al., 2008,

Massé et al., 2008; Roach et al., 2009; Wray et al., 2009]. At higher latitudes, Ca-sulfates have

been detected in dark dune fields in the vicinity of the North Polar Cap [Langevin et al., 2005b;

81 Roach et al., 2007] and possibly in the permafrost of the Phoenix landing site [Hecht et al., 2009].

82 Understanding the origin of these various kinds of sulfate-bearing deposits is of importance

83 because they constitute key elements to constrain the evolution of the Martian surface and past

84 climate. Various hypotheses have been suggested so far to explain their formation. On Earth,

85 large accumulations of sulfates commonly form in evaporitic environments [Rouchy and Blanc-

86 Valleron, 2006]; one of the classical hypotheses for the formation of sulfates on Mars is therefore

87 evaporitic concentration and deposition in water bodies [Catling, 1999]. Other classical

88 hypotheses involve in-situ weathering of sulphide deposits or basaltic materials by acid fogs or

89 acid groundwaters [see review in Chevrier and Mathé, 2007]. Recently, Niles and Michalski

90 [2009] suggested that Martian equatorial sulfates have formed by weathering of dust trapped in

91 ancient equatorial ice caps.

92 Interestingly, the largest accumulation of sulfates detected so far on Mars is located on

93 Olympia Planum, a crescent-shaped dome, $500 \mathrm{~km}$ in radius, located at the present-day border of

94 the North Polar Cap (Fig. 1a and b) [Langevin et al., 2005b; Roach et al., 2007]. This dome

95 corresponds to an ancient part of the North Polar Cap, which has been exhumed by erosional

96 retreat of its upper part [Zuber et al., 1998; Fishbaugh and Head, 2000, 2005]. This dome is now 
97 extensively covered by superficial sediment and dark dunes. These correspond to the densest part

98 of the Circum-Polar Dune Field that encircles the whole North Polar Cap [Fishbaugh et al., 2007;

99 Tanaka and Hayward, 2008]. The spectral signature of hydrated Ca-sulfate (most likely gypsum)

100 observed by OMEGA and CRISM in this region is correlated to the dark dunes that cover

101 Olympia Planum (Fig. 1b) [Langevin et al., 2005b; Roach et al., 2007].

102 The presence of gypsum in dunes resting on an erosional relict of the North Polar Cap raises

103 the question of whether a link exists between the processes of formation and/or accumulation of

104 these circum-polar sulfates and the past or present activity of the ice cap. The aim of our study is

105 therefore to evaluate, by an integrated morphological, structural and compositional analysis,

106 whether polar and circum-polar gypsum-rich deposits, such as those observed in Olympia

107 Planum, derive from the North Polar Cap or not.

108 For that purpose, we focus on a key area located at the border of the North Polar Cap,

109 between Olympia Cavi and Gemini Scopuli (Fig. 1a and 2). This area provides a comprehensive

110 view, on the same location, of (1) the Circum-Polar Dune Field, (2) the surface of the North Polar

111 Cap and (3) a natural cross-section that reveals the internal structure of the ice cap.

112 Morphological and structural information on this area is provided by the analysis of HiRISE and

113 CTX images and MOLA topographic data, while compositional constraints are provided by the

114 analysis of CRISM and OMEGA hyperspectral data.

115 In section 2, we briefly describe the North Polar Cap, the associated polar and circum-polar

116 superficial accumulations of dark sediment (including the Circum-Polar Dune Field) and we

117 review current hypotheses for the origin of the circum-polar sulfate deposits. Then, we introduce

118 in section 3 the structure and landforms of the study area and discuss their significance. In section

1194 , we present the results of the spectroscopic compositional analysis. We finally discuss in

120 section 5 the implications for the origin of polar and circumpolar sulfates. 


\section{2. Geological setting}

\section{$123 \quad$ 2.1 The North Polar Cap}

124 The North Polar Cap rests in the lowest part of the Vastistas Borealis topographic basin (Fig.

125 1a and c). It is $1300 \mathrm{~km}$ in diameter and reaches a maximum thickness of $3 \mathrm{~km}$ at its center

126 [Zuber et al., 1998]. The formation of the whole ice cap took place during the Amazonian [Carr

127 and Head, 2009]. It is a stack of water ice layers containing various amounts of intermixed

128 sediment (dust or sand) [Kieffer et al., 1976; Tsoar at al., 1979; Howard et al., 1982; Fishbaugh et

129 al., 2008]. Two distinct units have been recognized in this stack (Fig. 1c). The first one

130 corresponds to the Basal Unit (BU), which rests directly on the Vastistas Borealis Formation

131 (VBF). High-resolution images reveal that the BU consists of a low albedo, $1 \mathrm{~km}$-thick formation

132 displaying platy interbedded sequences of ice-rich and sediment-rich layers [Byrne and Murray,

133 2002; Edgett et al., 2003; Fishbaugh and Head, 2005]. SHARAD and MARSIS radar soundings

134 have confirmed the existence of this sediment-rich $\mathrm{BU}$, and have revealed that it is largely

135 confined to the major lobe of the North Polar Cap (Fig. 1) [Picardi et al., 2005; Phillips et al.,

136 2008; Putzig et al., 2009]. The second unit corresponds to the upper (and younger) part of the ice

137 cap, which is composed of the North Polar Layered Deposits (NPLD). On high-resolution

138 images, the NPLD appear brighter and more finely layered than the BU. The majority of the

139 NPLD is made of water ice and their layering results from varying fractions of included sediment

140 and/or varying ice grain sizes [Kiefer et al., 1976; Calvin et al., 2009]. Radar soundings have

141 confirmed that the amount of sediment in the NPLD is small, with only $\sim 2 \%$ for most layers and

$142 \sim 30 \%$ for a few strong radar reflective layers [Picardi et al., 2005; Phillips et al., 2008]. On the 
143 basis of morphological and sedimentary interpretation of high-resolution images, Tanaka et al.

144 [2008] subdivided the BU and the NPLD into a full suite of stratigraphic units.

145 The surface morphology of the North Polar Cap is dominated by interior spiral troughs and

146 marginal steep arcuate scarps [Howard, 2000] (Fig. 1a and c). These spiral troughs and arcuate

147 scarps provide natural cross-sections where the internal structure of the North Polar Cap can be

148 observed. Spiral troughs only cut through the NPLD and do not reach the BU [Putzig et al.,

149 2009]. The most widely accepted hypothesis for their formation is ablation due to katabatic winds

150 and sublimation [Howard, 2000; Ivanov and Muhleman, 2000]. Katabatic winds and sublimation

151 are most probably also responsible for the formation of the marginal arcuate scarps [Warner and

152 Farmer, 2008]. The correlation between the location of the arcuate scarps and the spatial extent of

153 the BU has been attributed to preferential undermining of the scarp bases because of the presence

154 of sand in the BU [Howard, 2000; Edgett et al., 2003].

155 During Martian winters, a layer of $\mathrm{CO}_{2}$ and $\mathrm{H}_{2} \mathrm{O}$ frost, approximately one meter in thickness,

156 covers the North Polar Cap. This seasonal frost coverage begins to sublimate in spring and has

157 disappeared by the end of summer [Smith et al., 2001b; Byrne et al., 2008].

$158 \quad 2.2$ Polar and circum-polar superficial accumulations of dark sediment

159 In addition to sediment intermixed in the ice of the BU and of the NPLD, dark polar and

160 circum-polar sediment has also been observed in the form of (1) superficial accumulations on the

161 floors of some spiral troughs, (2) extensive superficial mantles (classically named dark veneers

162 [Rodriguez et al., 2007]) covering the surface of the NPLD, and (3) dunes located in the Circum-

163 Polar Dune Field [Rodriguez et al., 2007; Horgan et al., 2009]. The sources of the dark veneers

164 and of the sedimentary accumulations in spiral troughs are sediment-rich layers of the NPLD

165 [Rodriguez et al., 2007; Tanaka et al., 2008]. 

constituting the Circum-Polar Dune Field have been classified as transverse and barchan dunes

169 [Tsoar et al., 1979]. Based on the shape of these dunes and on their systematic association with 170 arcuate scarps, Thomas and Weitz [1989] inferred that the source of the circum-polar dune

171 material is sand that was initially contained within the North Polar Cap. Herkenhoff and Vasada

172 [1999] thus conjectured that the dune material might be composed of filamentary sublimation

173 residue formed by concentration of dust in sand-size aggregates during sublimation of the ice cap.

174 Alternatively, it has been suggested that the major source for the circum-polar dune material is

175 sand derived from the BU rather than dust derived from the whole ice cap [Fishbaugh and Head,

176 2005; Herkenhoff et al., 2007].

\section{$177 \quad 2.3$ Sulfates in polar and circum-polar superficial sediment}

178 Spectroscopic studies have revealed unambiguous signatures of a calcium-rich hydrated 179 sulfate (most likely gypsum) on Olympia Planum (Fig. 1b) [Langevin et al., 2005b, Roach et al., 180 2007]. In this portion of the Circum-Polar Dune Field, the density of dunes is at its highest

181 [Tanaka and Hayward, 2008]. In the inter-dune substrate of Olympia Planum, Roach et al. [2007]

182 detected gypsum signatures, which appear weaker than those found on dunes. These weak

183 signatures indicate either that small amounts of fine-grained gypsum are present within the bulk

184 of the inter-dune substrate or that a thin layer of gypsum-rich particles covers the inter-dune 185 substrate.

186 Poulet et al. [2005], Horgan et al. [2009] and Calvin et al. [2009] detected spectroscopic 187 signatures of hydrated minerals on the entire Circum-Polar Dune Field, on the NPLD dark 188 veneers and on the sedimentary accumulations covering spiral troughs. It is unclear however 189 whether these signatures correspond to gypsum, to another kind of hydrated sulfate or more 
190 generally to any other hydrated minerals. If these signatures do correspond to gypsum, as they do

191 in Olympia Planum, their weakness has to be attributed either (1) to low gypsum concentrations,

192 (2) to scattering effects due to texture, or (3) to spatial exposures of gypsum being too small to be

193 resolved with the spatial resolution of the instrument [Calvin et al., 2009].

194 The darkness of the circum-polar sediments suggests that they are not pure gypsum. Poulet et

195 al. [2005] and Horgan and Bell [2009] have also identified signatures of mafic minerals, which

196 could explain their low albedo. Alternatively, Fishbaugh et al. [2007] suggested that secondary

197 oxides may darken these sediments.

$198 \quad 2.4$ Currently proposed origins for circum-polar sulfates

199 Because of its softness, gypsum is easily susceptible to physical weathering; therefore the

200 gypsum detected on Olympia Planum has probably formed in-situ or within a short distance from

201 its current location [Fishbaugh et al., 2007]. On this basis, Langevin et al. [2005b] suggested two

202 different hypotheses for the formation of gypsum in Olympia Planum: interaction of Ca-rich

203 minerals with snow containing $\mathrm{H}_{2} \mathrm{SO}_{4}$ derived from volcanic activity or formation as an evaporite

204 deposit after major meltwater outflows from the ice cap during warm climatic incursions.

205 Fishbaugh et al. [2007] suggested that water from nearby channels percolated through dunes that

206 cover the eastern end of Olympia Planum and attributed the formation of gypsum there to a

207 combination of (1) in-situ aqueous weathering of sulfide- and high-calcium-pyroxene-bearing

208 dune materials and (2) formation of evaporitic gypsum crystals in the pore spaces of these

209 materials. Szynkiewicz et al. [2010] suggested that gypsum crystals were formed by evaporation

210 of saline waters and were later transported by winds towards Olympia Planum.

211 Alternatively, it has been suggested that gypsum minerals could derive directly from the

212 underlying BU [Roach et al., 2007; Calvin et al., 2009]; this interpretation would be consistent 
213 with the possible existence of small amounts of gypsum in the inter-dune substrate [Roach et al.,

214 2007].

215 To further constrain the extent and the origin of polar and circum-polar sulfate deposits, we

216 focus on a key area which encompasses all the features described above (Fig. 2): (1) the surface

217 of the North Polar Cap, (2) two spiral troughs, (3) two marginal arcuate scarps providing natural

218 cross-sections through the NPLD and the BU and (4) a portion of the Circum-Polar Dune Field.

219 This area is located at the border of the North Polar Cap, between Olympia Cavi and Gemini

220 Scopuli, at the latitude of $83^{\circ} \mathrm{N}$ and the longitude of $118^{\circ} \mathrm{E}$. The portion of the Circum-Polar

221 Dune Field comprised in this study area is located outside the gypsum-rich area previously

222 identified by Langevin et al. [2005b] (Fig. 1b), but spectroscopic signatures of hydrated minerals

223 have been detected there [Horgan et al., 2009; Calvin et al., 2009]. Based on a detailed

224 morphological and compositional analysis of this area, we will demonstrate that gypsum is

225 present in all kinds of polar and circum-polar superficial accumulations of dark sediment, and

226 that it derives from the ice cap.

228 3. Structure and landforms of the study area

3.1. Data and Methods

230 We investigate the structure and landforms of the study area with complementary data sets,

231 which provide different kinds of information. All these datasets have been incorporated into a

232 geographic information system using the Mars 2000 geographic coordinate system and the polar

233 stereographic projection.

234 Topographic information is provided by the Mars Orbiter Laser Altimeter (MOLA). The

235 selected polar digital terrain model has a relative vertical accuracy of $1 \mathrm{~m}$ and an average spatial resolution of 512 pixel / degree [Smith et al., 2001a]. Geomorphological and structural 
237 information is provided by (1) images of the Context Camera (CTX) with a spatial resolution of 6

$238 \mathrm{~m} /$ pixel over a swath that is about $30 \mathrm{~km}$ wide [Malin et al., 2007], (2) images of the High

239 Resolution Imaging Science Experiment (HiRISE) with a resolution up to $30 \mathrm{~cm} /$ pixel for a

240 swath width of $6 \mathrm{~km}$ [McEwen et al., 2007]. Since we aim at observing sediment in the bulk and

241 at the surface of the permanent ice cap, we use CTX and HiRISE images acquired in summer

242 only, in order to minimize the effect of the seasonal $\mathrm{CO}_{2}$ and $\mathrm{H}_{2} \mathrm{O}$ frost coverage.

\section{3.2. Description of landforms in the study area}

244 A CTX image, an interpretative sketch-map and an interpretative cross-section of the whole

245 study area are shown in Fig. 3.

246 The surface of the NPLD occupies the northern half of the image. The outer reaches of two

247 spiral troughs strike NW-SE across the NPLD (Fig. 2 and 3). In the area encompassed by the

248 image, these troughs are 300 to $500 \mathrm{~m}$ deep. Unlike other spiral troughs observed elsewhere on

249 the North Polar Cap by Rodriguez et al. [2007] and Horgan et al. [2009], the troughs of the study

250 area are not covered by dark sediment. The internal layering of the NPLD is thus exposed in

251 these troughs. Differences in albedo between the exposed layers indicate either that they contain

252 differing amounts of sediment intermixed with the ice or that they have differing ice grain sizes

253 [Calvin et al., 2009]. Along the northern border of the northernmost trough, the surface of a

254 dissected packet of ice layers forms a tabular outcrop covered by dark sediment and bordered by

255 an escarpment 100 m-high (Fig. 3).

256 In the central-eastern and south-western parts of the image, two arcuate scarps, facing south,

257 cut through the NPLD (Fig. 2 and 3). The northernmost arcuate scarp is $\sim 25 \mathrm{~km}$ wide and extends

258 beyond the eastern border of the image; its maximal height is $500 \mathrm{~m}$. The southernmost one is

$259 \sim 20 \mathrm{~km}$ wide and extends beyond the western border of the image; its maximal height is $300 \mathrm{~m}$. 
260 The average slope gradient is $30^{\circ}$ in the steepest parts of both scarps. The two arcuate scarps

261 intersect, hence were probably carved later than, the spiral troughs.

262 These scarps provide vertical sections through the whole stack of NPLD present in this area,

263 and the BU that has been exhumed at their base (Fig. 3). The BU is distinguishable from the

264 NPLD by a break in topographic slope at the base of the scarps (Fig. 3c and d), by its darker tone

265 due to its larger concentration in sediment, and by the fact that the beds of the BU form resistant

266 shelves, and are organized in platy interbedded sequences of ice-rich and sediment-rich layers

267 (Fig. 3c). The fact that the BU crops out at the base of arcuate scarps in this region is consistent

268 with the extension of the BU as inferred from radar soundings [Putzig et al., 2009] (Fig. 1 and 2).

269 South of each scarp, the topographic surface dips gently northwards. In these latter regions,

270 superficial sediment and dunes of the Circum-Polar Dune Field cover the NPLD and the BU,

271 except for the southernmost part of the image where ice is visible (Fig. 3).

272 3.3. Release of dark superficial sediment towards dune fields by horizontal ablation of ice

273 layers at arcuate scarps

274 On Earth, the formation of steep arcuate marginal scarps is typical of those glaciers where

275 sublimation is the dominant process of ablation. These include equatorial glaciers such as those

276 located on the Kilimanjaro in Africa and polar glaciers such as those located in the Dry Valleys in

277 Antarctica. It has been shown that these steep terrestrial ice walls are erosional forms that move

278 backward by horizontal regressive ablation of the ice under the effect of radiant heating [Fountain

279 et al., 2006; Hoffman et al., 2008; Mölg and Hardy, 2004; Mölg et al., 2003, 2008]. We infer that

280 the steep arcuate scarps observed in the study area have formed by a similar process of horizontal

281 regressive ablation of the North Polar Cap. In the pressure and temperature conditions currently

282 prevailing at these latitudes on Mars, sublimation is the most probable process by which ablation

283 of ice and erosional retreat of the scarps may have occurred [Ivanov and Muhleman, 2000]. 
The substrate of the regions lying at the bottom of the two arcuate scarps comprises the BU and the NPLD (Fig. 3a, b, d). This substrate is covered by a superficial mantle of dark sediment and by dark dune fields. These are separated from the corresponding scarps by distances of 0 to 6 [1979] and Hayward et al. [2007], which are indicative of unidirectional winds [Bagnold, 1954].

The orientation of the dunes indicates that the dominant wind blows down scarp from the NE (Fig. 3a and b). particularly well defined for the northernmost field (Fig. 3a and b). The presence of this upwind belt is classical in terrestrial dune fields and can be explained by the fact that dunes of the first row lose less sand than they gain and turn into mega dunes [Bagnold, 1954; Tsoar et al, 1979]. At a distance of 0 to $900 \mathrm{~m}$ from their upwind border belts, both dune fields are constituted by smaller, closely packed, barchanoids. At the down-wind portions of the fields, the end barchans

297 have a tendency to disperse. This organization is consistent with the wind blowing dominantly 298 from the NE down the surface of the North Polar Cap and down the scarps. Frost streaks at the 299 surface of the NPLD also indicate that the wind blows dominantly from the NE (Fig. 3a).

300 At the feet of both scarps, dark streamers striking NE are visible (Fig. 3a and c). These

301 features indicate that dark sediment that has been released from ice layers ablated by the retreat

302 of the scarps was accumulated at their feet in the form of dark sublimation tills covering the 303 NPLD and the BU. This sediment is then transported by the wind towards the dune fields.

304 All of our observations in this region are thus consistent with the systematic association, 305 elsewhere around the North Polar Cap, of dune fields with arcuate scarps and with the 306 corresponding interpretation that the material present in the Circum-Polar Dune Field derives 307 from the North Polar Cap [Tsoar et al., 1979; Thomas and Weitz, 1989; Howard, 2000; Warner 
and Farmer, 2008]. We infer that this material (1) was released from the ice cap as the arcuate

309

310 scarps retreated by sublimation, (2) was then mobilized by katabatic winds descending along the surface of the North Polar Cap and (3) was eventually deposited in dune fields around the ice cap.

\subsection{Release of dark sediment at the surface of the NPLD by vertical ablation of ice layers}

The northern (south-facing) slope of the northernmost spiral trough is interrupted by an

escarpment $100 \mathrm{~m}$ high (Fig. 3). We interpret this scalloped escarpment as the erosional front of a dissected packet of ice layers (Fig. 4a and d). Above the escarpment is a $3 \mathrm{~km}$ wide topographic plateau entirely covered by dark sediment and corresponding to an erosional surface that developed at the expense of this packet of ice layers. Erosional remnants of the uppermost layers of the packet appear in the form of linear tongues and ovoid tabular ridges striking East-West, a few hundred meters in average width, that are entirely covered by dark sediment (Fig. 4a, b and d). At the center of some of these ovoid ridges is a depression where the superficial dark sediment is less abundant (Fig. 4a and b). These remnant buttes indicate that some ice layers, which formerly covered the whole plateau, have now been extensively dissected by erosion. Sublimation is the major process by which near complete ablation of these layers can have occurred in this region [Ivanov and Muhleman, 2000]. This interpretation is supported by the existence of similar landforms in terrestrial glaciers subjected to sublimation, such as on the Kilimanjaro [Mölg and Hardy, 2004; Mölg et al., 2003, 2008].

Between the remnant buttes, the plateau has a specific roughness, composed of closely spaced, regular, polygonal hollows (Fig. 4b). These hollows are 20 to $50 \mathrm{~m}$ in diameter and are separated from each other by ridges that form a "honeycomb-like network" [Milkovich and Head, 2006]. Differences in albedo between the hollow centers and the boundary ridges reveal that the sediment is denser on the ridges than in the hollows. This specific kind of surface texture is common on terrestrial glaciers and snowfields (Fig. 4c). It is known as ablation hollows or 
332 suncups [Rhodes et al., 1987; Betterton, 2001]. Terrestrial ablation hollows form through radiant

333 heating of the ice surface due to direct or indirect sunlight, which causes ablation of the ice by

334 melting or sublimation [Rhodes et al., 1987; Betterton, 2001; Milkovich and Head, 2006]. These

335 features grow because hollow centers receive more reflected light than ridges. As surface

336 lowering by ablation proceeds, any sediment particle that was initially present within the bulk of

337 the ice will move in a trajectory perpendicular to the surface and the sediment will thus

338 concentrate on the ridges [Rhodes et al, 1987]. Though they have not unambiguously observed

339 them, Milkovich and Head [2006] postulated that ablation hollows likely exist on the North Polar

340 Cap of Mars. On Earth, these features generally form by surface melting. By contrast, under the

341 pressure and temperature conditions prevailing at these latitudes on Mars, the development of

342 ablation hollows most probably involves sublimation [Ivanov and Muhleman, 2000; Milkovich

343 and Head, 2006]. The difference in size between terrestrial ablation hollows (typically $0.1-1 \mathrm{~m}$

344 in diameter) and those described here $(20-50 \mathrm{~m})$ is attributable to either (1) differences in initial

345 sediment concentration within the ice, (2) differences in conditions of radiant heating, (3)

346 differences in the process of ablation (melting on Earth versus sublimation on Mars) or (4)

347 differences in the time available for their development (one season at most on Earth versus

348 several years at least on Mars). The effect of each these various parameters on the size of ablation

349 hollows is poorly known because of the lack of measurements and physical models on their

350 development. Betterton (2001) however demonstrated that the amount of sediment strongly

351 controls the size of suncups and it seems reasonable to assume that longer development times will

352 help create larger features.

353 Our observations on this dissected plateau thus demonstrate the presence of a superficial

354 accumulation of sediment on an ablation surface that developed at the expense of a packet of ice

355 layers. The concentration of this superficial sediment on ridges forming a honeycomb-like 
network is best explained by a process, well known on terrestrial glaciers, according to which the

357

sediment that was initially present within the bulk of the ice has concentrated at the surface by vertical ablation of the ice.

This interpretation is supported by the fact that this superficial accumulation of sediment can be traced from place to place, along the same sub-horizontal ice layers, throughout the study area (Fig. 3a, b and d). Had this sediment been imported from elsewhere and had it been deposited unconformably from above after the formation of the ablation surface, its extent would not fit that of the ice layers. We thus infer that the superficial sediment covering the plateau has been released from the eroding packet of ice layers itself (Fig. 3d); it has concentrated in the form of a sublimation till on the surface of the ice cap, as ablation by sublimation dissected this sedimentrich packet of ice layers.

\subsection{Synthesis: origin of polar and circum-polar accumulations of dark sediment}

We have shown that in the region under study, dune fields are fed by sediment released from arcuate scarps that develop by regressive ablation of the North Polar Cap. This sediment may derive either from the BU exhumed at the base of the arcuate scarps or from the NPLD that covered the area before erosional retreat of the arcuate scarps. We have also shown evidence that sediment accumulations at the surface of the NPLD are released by vertical ablation of sedimentrich ice layers of the NPLD.

As a conclusion, the superficial sediment present on the NPLD and in the Circum-Polar Dune Field derives from the North Polar Cap. This sediment, which was initially intermixed within the bulk of the ice, now forms ablation tills that have concentrated at the ice surface by sublimation. Katabatic winds are responsible for its re-mobilization and its deposition in the Circum-Polar Dune Field. Previous observations elsewhere on the North Polar Cap are consistent with this interpretation [Tsoar et al., 1979; Thomas and Weitz, 1989; Herkenhoff and Vasada, 1999; 

and Farmer, 2008].

\section{Mineralogical analysis}

Two different hypotheses remain for the origin of gypsum crystals that have been observed in

Similarly to the dark sediment described in part 3, gypsum crystals may have been initially by ablation, and transported towards dunes [Calvin et al., 2009]. Alternatively, they may have formed as secondary minerals in dunes, at the expense or in the pore spaces of the dark sediment derived from the North Polar Cap [Langevin et al., 2005b; Fishbaugh et al., 2007]. To evaluate the validity of the first hypothesis, we must be able to detect the presence of gypsum in the North Polar Cap from orbital hyperspectral data. For that purpose, we have first investigated the spectral behavior of experimental ice-gypsum mixtures in Martian pressure and temperature conditions. The results of this laboratory study were then used to derive the composition of sediments associated with the North Polar Cap from the available orbital hyperspectral data.

\subsection{Spectral behavior of experimental ice-gypsum mixtures}

\subsubsection{Experimental procedure}

398 In order to investigate the spectral behavior of ice-gypsum mixtures, we have acquired

399 laboratory reflectance spectra of ice samples containing various volumetric proportions of

400 gypsum. The ice was produced by condensation of liquid water on a cooled metal plate [Dupire et

401 al., 2009]. It was then crushed to obtain grain sizes between 500 and $600 \mu \mathrm{m}$. These ice grains

402 were homogenously mixed with an industrial pure gypsum powder (producer: Merck Chemicals;

403 reference: 102160 , commercial name: calcium sulfate dihydrate precipitated, chemical formula: 
$404 \mathrm{CaSO}_{4} * 2 \mathrm{H}_{2} \mathrm{O}$, grain size: less than $\left.10 \mu \mathrm{m}\right)$. The samples were then placed in a liquid nitrogen

405 cryostat (MicrostatN, Oxford Instruments) to reproduce the Martian pressure and temperature

406 conditions ( 7 mbar, $150 \mathrm{~K}$ ) and their spectra were acquired with a Nicolet 5700 Fourier

407 Transform Infrared Spectrometer, which collects 4149 spectral channels from 1 to $5 \mu \mathrm{m}$.

408 4.1.2. Results

409 Fig. 5 displays the laboratory spectra obtained for pure water ice, pure gypsum, a mixture

410 composed of $\sim 50 \%$ ice and $\sim 50 \%$ gypsum in volume and a mixture composed of $\sim 30 \%$ ice and

$411 \sim 70 \%$ gypsum in volume. Pure water ice displays specific absorption bands at $1.04 \mu \mathrm{m}$ and 1.25

$412 \mu \mathrm{m}$, two broad absorption bands between 1.50 and $1.66 \mu \mathrm{m}$ and between 1.96 and $2.05 \mu \mathrm{m}$ and,

413 one band at $2.55 \mu \mathrm{m}$. Pure gypsum exhibits one absorption band centered at $1.20 \mu \mathrm{m}$ (due to $\mathrm{H}_{2} \mathrm{O}$

414 combinations), a triplet of absorption bands of progressively decreasing intensity at 1.44, 1.49

415 and $1.53 \mu \mathrm{m}$ (due to $\mathrm{O}-\mathrm{H}$ stretches), and a band at $1.74 \mu \mathrm{m}$ (due to an $\mathrm{OH}$ combination), a double

416 band near 1.94 and $1.97 \mu \mathrm{m}$ (due to $\mathrm{H}_{2} \mathrm{O}$ combinations), a broad band centered at $2.2 \mu \mathrm{m}$

417 constituted of two narrower components centered at 2.21 and $2.27 \mu \mathrm{m}$ (due to $\mathrm{H}_{2} \mathrm{O}$ combinations

418 and/or S-O stretching overtones), and a band centered at $2.48 \mu \mathrm{m}$ (due to S-O stretching

419 combinations) [Cloutis et al., 2006; 2008]. When gypsum is mixed with water ice, the spectral

420 behavior of the mixture may be described as follows.

$421 \quad$ - The gypsum absorption band at $1.20 \mu \mathrm{m}$ is masked by the ice band at $1.25 \mu \mathrm{m}$ even at high

422 gypsum concentrations. Therefore the band at $1.20 \mu \mathrm{m}$ cannot be used to detect gypsum when it

423 is mixed with ice.

$424-$ Gypsum absorption bands remain visible at $1.44,1.49$ and $1.53 \mu \mathrm{m}$. However, the bands at

425 1.49 and $1.53 \mu \mathrm{m}$ are small and are close to the center of the broad ice band at $1.50 \mu \mathrm{m}$.

426 Therefore these two bands cannot be reliably discriminated from the $1.50 \mu \mathrm{m}$ ice band. The 1.44 
427

428

429

430

431

432

433

434

435

436

437

438

439

440

441

442

443

444

445

446

447

448

449

$\mu \mathrm{m}$ absorption band is sufficiently far from the center of the $1.50 \mu \mathrm{m}$ ice band, that it remains visible at high gypsum concentrations and disappears progressively with increasing ice content.

- The gypsum absorption band at $1.74 \mu \mathrm{m}$ turns into an inflexion at high gypsum concentrations and disappears at high ice concentrations.

- The 1.94 and $1.97 \mu \mathrm{m}$ gypsum absorption bands remain visible even at high ice concentrations distorting the $2 \mu \mathrm{m}$ water ice band.

- The broad gypsum absorption band at $2.2 \mu \mathrm{m}$ disappears and only its two narrow components at 2.21 and $2.27 \mu \mathrm{m}$ remain on the wings of the ice peak centered at $2.24 \mu \mathrm{m}$. At low gypsum concentrations, these two bands turn into residual inflexions on both sides of the ice peak.

- The $2.48 \mu \mathrm{m}$ gypsum absorption band is close to the center of the broader $2.55 \mu \mathrm{m}$ water ice band, and is therefore difficult to isolate.

To summarize, laboratory spectra show that, when gypsum is mixed with water ice, diagnostic gypsum absorption bands remain at 1.44, 1.74, 1.94, 2.21, 2.27 and $2.48 \mu \mathrm{m}$, but all of these bands are very shallow and may be overlapped by those of water ice. These bands are thus predictably difficult to detect in spectra acquired remotely of ice-rich regions on natural planetary surfaces. In addition, currently available Martian data are noisier than laboratory spectra and their spectral resolution is lower. We have therefore developed specific spectral processing methods to detect and to isolate these shallow diagnostic bands on Martian hyperspectral data.

\subsection{Analysis of hyperspectral data in the study area}

\subsubsection{Data}

The mineralogical composition of the study area was investigated from data acquired by the OMEGA and CRISM imaging spectrometers. We selected data acquired in summer (OMEGA 
450 cube ORB1056_2 and CRISM cube hrl0000330c) to minimize the contribution of the seasonal

$451 \quad \mathrm{CO}_{2}$ and $\mathrm{H}_{2} \mathrm{O}$ frost coverage.

452 OMEGA (Observatoire pour la Mineralogie, l'Eau, les Glaces et l'Activite) [Bibring et al., 453 2004], onboard Mars Express, acquires hyperspectral images at a spatial resolution ranging from

$454300 \mathrm{~m}$ to $4.8 \mathrm{~km}$ per pixel. A spectrum is acquired in 352 spectral channels from 0.38 to $5.2 \mu \mathrm{m}$

455 for each pixel of an image, thus producing data cubes. CRISM (Compact Reconnaissance

456 Imaging Spectrometer for Mars) [Murchie et al., 2007] is onboard Mars Reconnaissance Orbiter

457 (MRO). In the targeted hyperspectral mode, CRISM collects 544 spectral channels from 0.36 to

$458 \quad 3.9 \mu \mathrm{m}$ at a spatial resolution ranging from 15 to $19 \mathrm{~m} / \mathrm{pixel}$.

459 We restricted our analysis to the spectral domain comprised between 1.0 and $2.5 \mu \mathrm{m}$. In this 460 wavelength range, the solar reflected light dominates the spectrum, and the thermal emission is 461 negligible [Gendrin et al., 2005]. This range is also suitable for the detection of hydrated minerals 462 commonly identified on Mars, and is particularly diagnostic for gypsum. In order to avoid the

463 effect of the CRISM smile [Murchie et al., 2007], we studied only the center of the image.

\section{4.2.2. Extraction of the spectral information}

465 4.2.2.1. Data reduction

466 OMEGA and CRISM spectra are acquired remotely through the atmosphere. In order to

467 extract the spectral contribution of the surface only, the atmospheric spectral contribution is 468 removed by using an empirical atmospheric transmission law derived from the ratio between two 469 spectra acquired at the summit and the base of the Olympus Mons volcano, and scaled to the 470 depth of the $\mathrm{CO}_{2}$ band [Langevin et al., 2005a; McGuire et al., 2009]. The CRISM Analysis 471 Toolkit (CAT) also corrects the photometric angles [Murchie et al., 2007]. Custom software 472 routines are used to georeference the OMEGA and CRISM images in the Mars 2000 coordinate 473 system with a polar stereographic projection. 


\subsubsection{Denoising}

The experimental study of the spectral behavior of gypsum-ice mixtures described in part 4.1 suggests that most bands diagnostic of gypsum are close to the noise level in unprocessed Martian data. Different kinds of denoising procedures have thus been applied to CRISM and OMEGA data.

The CIRRUS tool, available in the CAT, was applied to the CRISM cube. CIRRUS first removes isolated noise spikes with the "despiking" tool and then corrects the column bias with the "destriping" tool [Parente, 2008]. We have also performed a Minimum Noise Fraction (MNF) transform on OMEGA and CRISM data. This procedure, available in the ENVI software, segregates the noise from the information in the data. An inverse MNF transform computed only on the components containing the information can be used to decrease the noise level in the data cube [Green et al., 1988].

\subsubsection{Definition of spectral criteria}

To identify spectral features (e.g. absorption bands, spectral slopes) that are diagnostic of minerals, we have computed spectral criteria. These correspond to combinations of reflectance measured at different wavelengths. In order to further decrease the contribution of noise when computing these spectral criteria, the reflectance at a given wavelength was taken as the median of the values of reflectance measured in three adjacent instrumental channels centered on this wavelength. Spectral criteria were computed for each pixel of a cube, and maps of each spectral criterion were then produced.

We mapped the distribution of water ice with the calculation of the $1.5 \mu \mathrm{m}$ absorption band depth. This criterion is defined as follows:

$$
B D(1.50)=1-\frac{R(1.50)}{(0.7) * R(1.37)+(0.3) * R(1.82)}
$$


where $\mathrm{R}(\mathrm{x})$ is the value of reflectance corresponding to the wavelength at $\mathrm{x} \mu \mathrm{m}$.

On Mars, hydrated minerals such as gypsum have classically been identified with spectral

499 criteria based on the depth of the 1.4 and $1.9 \mu \mathrm{m}$ absorption bands [e.g. Pelkey et al., 2007;

500 Massé et al., 2008]. However, these criteria cannot be used to detect hydrated minerals when they

501 are mixed with ice because the broad 1.5 and $2.0 \mu \mathrm{m}$ water ice bands overlap the 1.4 and $1.9 \mu \mathrm{m}$

502 mineral hydration bands. Therefore, we used the criterion defined by Horgan et al. [2009] to

503 isolate the $1.9 \mu \mathrm{m}$ hydration band. This criterion is based on the assumption that the water ice

504 band at $2.0 \mu \mathrm{m}$ is symmetrical and that the addition of hydrated minerals imposes a slight

505 asymmetry to this band. This criterion is defined as follows:

506

507

$$
B D(1.934)=1-C R 1934 / C R 2108
$$

$$
C R(x)=R(x) /\left(\left[\frac{R(2.205)-R(1.842)}{2.205-1.842}\right](x-1.842)+R(1.842)\right)
$$

508

$509 \quad$ The same method cannot be used to isolate the $1.4 \mu \mathrm{m}$ hydration band from the $1.5 \mu \mathrm{m}$ water

510 ice band because the broad water ice band centered at $1.5 \mu \mathrm{m}$ is not symmetrical. Similarly, the

5112.21 and $2.27 \mu \mathrm{m}$ gypsum absorption bands interfere with the ice peak centered at $2.24 \mu \mathrm{m}$. In

512 addition, the $1.74,2.21$ and $2.27 \mu \mathrm{m}$ gypsum bands appear as inflexions rather than as deep bands

513 when gypsum is mixed with ice. Therefore all these bands, which are diagnostic of gypsum,

514 cannot be detected by computing simple spectral criteria. Hence, we have therefore used a

515 complementary method to monitor these specific shallows bands.

\subsubsection{Spectral derivative method}

517 The spectral derivative method has been initially developed to analyze terrestrial

518 hyperspectral data. It allows one to determine the wavelength position of narrow bands and to 
519 resolve overlapping absorption bands [Huguenin and Jones, 1986; Talsky, 1994; Tsai and

520 Philpot, 1998; Louchard et al., 2002, Verpoorter et al., 2007, Verpoorter, 2009; Verpoorter et al.,

521 2010]. This method has the advantage of being less dependent on the shape of the continuum and

522 thus removes background signals caused, for example, by differences in grain sizes or variations

523 in topography and illumination conditions. The method is based on the principle that absorption

524 bands constitute local minima in the spectrum (Fig. 6). They will therefore appear as zeros in the

525 first order derivative of the spectrum and as maxima in its second order derivative. On the other

526 hand, peaks between absorption bands constitute local maxima in the spectrum. They will

527 therefore appear as zeros in the first order derivative and as minima in the second order derivative

528 (Fig. 6). Inflexions will appear as local maxima or minima in the first order derivative and as

529 zeros in the second order derivative (Fig. 6). By the systematic detection of local minima, local

530 maxima and inflexions in a reflectance spectrum, the derivative method thus allows the

531 identification of the exact center of absorption bands, even for shallow or overlapping ones, and

532 independently from background signals. This technique enhances subtle fluctuations in

533 reflectance spectra and separates closely related absorption features.

534 We have adapted this method to detect all local minima in hyperspectral cubes and to produce

535 maps of their geographical distribution [Verpoorter, 2010]. The algorithm first detects the

536 wavelengths of all local minima in the spectra of all pixels of a cube. Then it produces, for each

537 identified wavelength, a map of the distribution of pixels where this wavelength corresponds to a

538 local minimum. Finally, a density map is produced for each identified wavelength by counting, in

539 a moving kernel (3x3), the number of pixels that display a local minimum at this wavelength.

$540 \quad 4.3$. Results

541 The histogram in Fig. 7 shows the frequency of all absorption bands detected by the spectral

542 derivative method in the whole CRISM cube. Fig. 8 displays representative CRISM spectra of the 
543 morphological units described in part 3. Maps of spectral criteria and maps of absorption bands

544 detected by the spectral derivative method are given in Fig. 9 and 10. Maps of spectral criteria

545 provide quantitative information such as band depths, whereas maps derived from the spectral

546 derivative method show the distribution of pixels where an absorption band is present at a given

547 wavelength. The spectral derivative method enhances all the spectral fluctuations and is thus very

548 sensitive. Therefore, overlapping absorption bands and weak spectral features that would not be

549 detected by computing spectral criteria, are readily identified by the spectral derivative method.

550 On the other hand, strong denoising must be performed before applying the spectral derivative

551 method. In some cases, this denoising can lead to the loss of some of the faintest absorption

552 bands. Our interpretation is therefore based on the joint analysis of both kinds of maps. To finally

553 ensure that a given local minimum detected by the spectral derivative method corresponds to an

554 absorption band rather than to residual noise, we check that pixels displaying this local minimum

555 define a spatially and geologically consistent area.

556 4.3.1. Absorption bands detected in the study area

557 Fig. 7 shows the distribution of absorption bands that more than $50 \%$ of the pixels in the

558 image display absorption bands centered at 1.50, 1.96 and $2.06 \mu \mathrm{m}$. Between $20 \%$ and $50 \%$ of

559 the pixels display absorption bands at 1.07, 1.22, 1.37, 1.92, 2.14, 2.21 and $2.27 \mu \mathrm{m}$. Absorption

560 bands are also detected at 1.30, 1.42, 1.57, 1.64, 1.73, 1.79, 1.86, 2.00 and $2.48 \mu \mathrm{m}$ on less than

$56120 \%$ of the pixels.

\section{4.3.2. Mineralogical interpretation}

563 The absorption bands detected at 1.07, 1.22, 1.30, 1.50, 1.64, 1.96, 2.00 and $2.06 \mu \mathrm{m}$ are

564 consistent with those of water ice. However, the absorption bands at 1.96, 2.00 and $2.06 \mu \mathrm{m}$ may

565 be artifacts due to the fact that the CRISM atmospheric correction fails between 1.97 and 2.08

$566 \mu \mathrm{m}$. The absorption bands at 1.22 and $1.64 \mu \mathrm{m}$ could also correspond to CRISM artifacts and the 
absorption bands at 1.07 and $1.30 \mu \mathrm{m}$ could be attributed to other components. We have thus

568 only used the $1.50 \mu \mathrm{m}$ absorption band to discriminate the water ice signature. This water ice

569 absorption band appears most distinctly on clean ice layers of the NPLD (Fig. 8, 9a and 9d). The

$570 \quad 1.50 \mu \mathrm{m}$ water ice absorption band is also shallower on sediment-rich ice layers of the NPLD and

571 on the polar and circum-polar superficial accumulations of dark sediment (Fig. 8, 9a and 9d).

572 These include the sublimation till covering the surface below arcuate scarps, the arcuate scarps

573 themselves, the sublimation till covering the dissected packet of NPLD ice layers described in

574 part 3.4 and the dunes.

575 The absorption bands detected at 1.42, 1.73, 1.92, 2.21, 2.27 and $2.48 \mu \mathrm{m}$ are consistent with

576 those of gypsum mixed with ice, as we have identified them experimentally (Fig. 5). These

577 gypsum absorption bands are spatially anti-correlated to those of water ice (Fig. 9). By contrast,

578 they are correlated with the polar and circum-polar superficial accumulations of dark sediment

579 (Fig. 8, 9b, 9c, 9e, 9f, 9g, 9h, 9i, 9j and 10). More specifically, they are present on the

580 sublimation till covering the BU and the NPLD below arcuate scarps (Fig. 8, 10e and 10f), on the

581 dunes (Fig. 8, 10e and 10f), on the dark streamers (Fig. 8, 10e and 10f), on the sediment-rich ice

582 layers of the arcuate scarps (Fig. 8, 10e and 10f), and on the sublimation till covering the

583 dissected packet of NPLD ice layers described in part 3.4 (Fig. 8, 10b and 10c).

$584 \quad$ The $1.42,1.92,2.21$ and $2.27 \mu \mathrm{m}$ gypsum absorption bands are well expressed on all of these

585 superficial sedimentary accumulations (Fig. 9c, 9f, 9h and 9i) (corresponding to more than 20\%

586 of the pixels in the image, Fig. 7), while the $1.73 \mu \mathrm{m}$ gypsum absorption band appears

587 dominantly on sediment-rich layers of the arcuate scarps and on dune crests, and the $2.48 \mu \mathrm{m}$

588 gypsum absorption bands appear dominantly on dune crests (Fig. 9e and 9j). As we have shown

589 experimentally, this difference can be attributed to the fact that the gypsum/ice mixing ratio is

590 higher in the dunes than in the sublimation tills. This interpretation is consistent with the 
591 observation in Olympia Planum that the strongest gypsum signature is located on dune crests

592 rather than on interdunes [Roach et al., 2007; Calvin et al., 2009].

593 An absorption band centered at $2.14 \mu \mathrm{m}$ is present on $30 \%$ of the pixels in the image and is

594 well visible both on raw and denoised CRISM spectral data (Fig. 7 and 8). This band is spatially

595 correlated with the gypsum absorption bands and is characteristic of the dark polar and circum-

596 polar sediment (Fig. 8 and 9g). Few common terrestrial minerals display an absorption band at

597 this wavelength. This band could correspond to perchlorate, a mineral uncommon on Earth but

598 that has been detected in the Martian permafrost at the Phoenix landing site [Hecht et al., 2009]

599 and that displays a deep diagnostic absorption band at this wavelength [Hanley et al., 2009;

600 Hanley et al., 2010; Morris et al., 2009]. It is interesting to notice that the possible presence of

601 perchlorate could have some important implications on the flow of the North Polar Cap [Fisher et

602 al., 2010]. As an alternative to perchlorate, the sulfite hannebachite $\left(2 \mathrm{CaSO}_{3} * \mathrm{H}_{2} \mathrm{O}\right)$ has also a

603 strong absorption band at $2.14 \mu \mathrm{m}$. As perchlorate has already been detected on Mars by the

604 Phoenix lander, we favor perchlorate to interpret the absorption band at $2.14 \mu \mathrm{m}$. However, the

605 presence of hannebachite cannot be ruled out since it would be consistent with the chemical

606 model of Halevy and Schrag [2009] showing that SO2 on Mars prevents the formation of calcium

607 carbonate in favor of this hydrated calcium sulfite.

608 Interestingly, gypsum and possibly perchlorate are present also in the bulk of sediment-rich

609 ice layers of the NPLD. Absorption bands at 1.93, 2.21 (gypsum) and $2.14 \mu \mathrm{m}$ (perchlorate?) are

610 visible directly on spectra acquired on sediment-rich ice layers (Fig. 8) and spectral criterion

$611 \mathrm{BD}(1.934)$ computed on raw data recognizes the $1.93 \mu \mathrm{m}$ band on all the sediment-rich ice layers

612 (Fig. 9b). With the spectral derivative method applied on denoised data, we detect the absorption

613 bands at 1.93, 2.14 and $2.21 \mu \mathrm{m}$ only in the most sediment-rich ice layers close to the dissected 
614 packet of NPLD (Fig. 9f, 10b and 10c), because these very shallow, narrow bands are easily

615 erased by the the denoising procedure.

616 Other local minima detected by the spectral derivative method at $1.37,1.57,1.79$ and 1.86

$617 \mu \mathrm{m}$ are more difficult to interpret. They might correspond to unidentified minerals or to spectral

618 noise (Fig. 7).

619 4.3.3. Regional validation with OMEGA data

Figure 11

Figure 12

620 In order to validate the absorption bands detected in the study area and to check the

621 consistency of these detections over a wider portion of the North Polar Cap, we applied the same

622 processing methods to OMEGA data.

623 Spectra acquired on dunes and on sublimation tills covering the North Polar Cap display the

624 same absorption bands, both on CRISM and OMEGA data (Fig. 11). This demonstrates that they

625 have similar mineralogical compositions. The most subtle bands barely show up on OMEGA data

626 however, due to the lower spatial resolution of the instrument, which induces higher spatial

627 mixing. On a regional scale, absorption bands at 1.42, 1.92, 2.21 and $2.27 \mu \mathrm{m}$, which are

628 diagnostic of gypsum, and an absorption band at $2.14 \mu \mathrm{m}$, which might be attributed to

629 perchlorate, are found to be systematically correlated to sediment-rich areas (Fig. 12b, 12d, 12e,

$63012 \mathrm{f}$ and $12 \mathrm{~g}$ ) and anti-correlated with water ice-rich areas (Fig. 12a and 12c). These include the

631 whole portion of the Circum-Polar Dune Field enclosed in the OMEGA cube and a significant

632 number of pixels on the North Polar Cap, corresponding to sublimation tills, to arcuate scarps and

633 to spiral troughs covered by superficial sediment (Fig. 12b, 12d, 12e, 12f and 12g).

635 5. Discussion

636 The mineralogical interpretation of CRISM and OMEGA hyperspectral data reveals that all

637 kinds of polar and circum-polar superficial accumulations of dark sediment present in the study 
638 area (including sublimation tills at the surface of the North Polar Cap and dunes in the Circum-

639 Polar Dune Field) display similar absorption bands (Fig. 8, 9, 10, 11 and 12). This indicates that

640 they have similar mineralogical compositions. They are a mixture of ice and various minerals

641 including gypsum and possibly perchlorate. Sediment with a similar composition is intermixed in

642 the ice of the North Polar Cap. The interpretation of landforms in the study area reveals that the

643 gypsum-bearing sediment present at the surface of the ice cap and in the Circum-Polar Dune

644 Field was released from the ice cap by sublimation. We infer that gypsum crystals that are now

645 present in the Circum-Polar Dune Field derive also from the North Polar Cap (Fig. 13). Dunes are

646 necessarily composed of grains with a size of a few hundreds of microns [Bagnold, 1954]. This

647 does not necessarily mean that the gypsum crystals derived from the ice cap must be so large. As

648 suggested by Herkenhoff and Vasada [1999], the grains in the dunes may be composed of smaller

649 gypsum crystals aggregated with ice and other minerals.

650 Two hypotheses remain for the ultimate origin of the gypsum crystals in the ice cap. (1) Pre-

651 existing gypsum crystals might have been deposited together with ice crystals during the

652 formation of the ice cap or (2) authigenic gypsum crystals might have grown within the ice cap

653 by weathering of sediment trapped in the ice. We have no means to answer this question directly

654 from currently available observations on Mars, but comparisons with terrestrial analogues might

655 be meaningful.

656 Sulfate salt inclusions have been found in Greenland and Antarctica ice cores, with gypsum

657 being the dominant salt species in layers deposited during glacial stages and $\mathrm{Na}$ - and/or $\mathrm{Mg}-$

658 sulfates being dominant in layers deposited during interglacial stages [Ohno et al., 2006]. The

659 amount of each salt species in the ice depends on the ion balance and the priority sequence of

660 chemical reactions. This priority sequence has been identified to be (1) calcium sulfate, (2) other

661 sulfates, (3) nitrates, (4) chlorides and (5) carbonates [Iizuka et al., 2008]. Sulfate crystals, and 
662 particularly gypsum, are thus common in terrestrial glaciers. On Mars, the sequence of salts

663 formation may be slightly different, but Tosca et al. [2006] demonstrated that gypsum is the first

664 salt to form when $\mathrm{SO}_{4}{ }^{2-}$ is sufficiently abundant.

665 Sulfate crystals found in terrestrial glaciers can form in the atmosphere, prior to their

666 deposition, by the neutralization of volcanic $\mathrm{H}_{2} \mathrm{SO}_{4}$ on dust containing $\mathrm{Ca}^{2+}, \mathrm{Na}^{+}$or $\mathrm{Mg}^{2+}$ [Iizuka

667 et al. 2006 and 2008]. Postdepositional processes also can affect the abundances and forms of ion

668 species. These postdepositional processes include: (1) reworking and mixing of the surface snow

669 by winds, (2) sublimation, condensation and volatilization in surface snow and (3) molecular

670 diffusion in firn or ice. By this way, sulfate crystals can also form directly in the ice when liquid-

671 phase $\mathrm{SO}_{4}{ }^{2-}$ diffuses to relatively immobile $\mathrm{Ca}^{2+}, \mathrm{Na}^{+}$or $\mathrm{Mg}^{2+}$ [Iizuka et al., 2006; 2008].

672 To conclude, sulfate crystals that are present in the Earth's closest cold-desert analogs for the

673 Martian North Polar Cap, have probably formed both in the atmosphere and in the ice [Iizuka et

674 al., 2006 and 2008]. By the same way, gypsum crystals that are present in the North Polar Cap of

675 Mars may be both: (1) pre-existing gypsum crystals that have formed in the atmosphere and have

676 been deposited together with ice crystals during the formation of the ice cap and (2) authigenic

677 gypsum crystals that have formed in the ice cap by post-depositional processes.

678 A genetic link between sulfates and ice bodies has been suggested previously to explain the

679 formation of ancient sulfate deposits in equatorial regions of Mars [Niles and Michalski, 2009].

680 These authors argue that ice bodies with intermixed sediment, similar to the Polar Layered

681 Deposits that are currently present in the North and South Polar Caps, have formed in equatorial

682 regions of Mars during former periods of high obliquity or polar wander. Within these massive

683 ice deposits, acid weathering of the intermixed sediment would have led to the formation of

684 sulfates. Later, aeolian reworking of the sublimation residue of this mixture of ice and sulfates

685 would have formed the equatorial sulfate-bearing sediments. This model is consistent with recent 
results of thermodynamical models, which indicate that low-temperature acid weathering of basaltic dust with small amounts of liquid water can lead to the formation of sulfates in a few decades only [Berger et al., 2009]. According to Niles and Michalski [2009], their ice-weathering model resolves many chemical and morphological problems highlighted by previous hypotheses concerning the formation of equatorial sulfates on the Martian surface. In equatorial regions, the ancient accumulations of intermixed ice and sediment required by the model have disappeared.

692 Therefore, the ice-weathering model is difficult to evaluate directly in these regions. Our results

693 however demonstrate that recent polar and circum-polar sulfate deposits derive from the North

694 Polar Cap and thus support the possibility that similar processes may have occurred at lower 695 latitudes in the past.

\section{Conclusion}

The development of a spectral processing method based on spectral derivation allows and in the Circum-Polar Dune Field. We find that the hydrated minerals detected by Horgan et al. [2009] and Calvin et al. [2009] in the study area correspond to gypsum and possibly perchlorate.

Therefore, the presence of gypsum is not restricted to the Olympia Planum dunes but can probably be extended to the whole Circumpolar Dune Field. Gypsum is also found on all the superficial sediment present in the study area including: sublimation tills at the surface of the NPLD and the BU, sediment-rich ice layers and dark streamers released from the polar cap. We

707 thus deduce that circumpolar gypsum has not formed by in-situ weathering of the dunes but was

708 initially present in the North Polar Cap and has been released to the surface by the ablation of the 709 ice. This morphological and mineralogical study also shows that sediment constituting the 
710 circumpolar dunes originates both from the NPLD and the BU. The proportion of sediment

711 intermixed with ice is smaller in the NPLD than in the BU [Picardi et al., 2005; Phillips et al.,

712 2008], therefore the majority of the dune material is probably provided by the BU.

713 According to these results we propose the following scenario for the formation of polar and

714 circum-polar sulfate-bearing deposits on Mars (Fig. 13).

715 1. Gypsum crystals form in the atmosphere and/or in the ice cap by neutralization of

716 volcanic $\mathrm{H} 2 \mathrm{SO} 4$ on Ca-bearing sediment.

2. These gypsum crystals are trapped in the ice.

718 3. Erosion of the ice cap by winds and sublimation leads to the formation of spiral troughs, 719 arcuate scarps and other ablation landforms.

720 4. As erosion proceeds, gypsum crystals are released from the ice and they concentrate in 721 sublimation tills at the surface of the ice cap.

722 5. Gypsum-bearing sublimation tills are reworked by winds and transported towards the

723 Circum-Polar Dune Field.

724 This scenario is consistent with the observation of sulfate crystals, and particularly gypsum,

725 in Greenland and Antarctic ices cores, which form both by predepositional processes in the

726 atmosphere and postdepositional processes in the ice [Ohno et al., 2006; Iizuka et al., 2006 and

727 2008]. It may also provides a basis, derived from the analysis of processes recently active in the

728 polar regions of Mars, to constrain the processes that were responsible for the formation of

729 sulfate-bearing deposits at lower latitudes in the past.

730

731 Acknowledgments

732 This work benefited from financial supports from the Centre National de la Recherche

733 Scientifique, Institut National des Sciences de l'Univers (Programme National de Planétologie), 
734 and from the Centre National d'Etudes Spatiales. M. Massé is supported by a Ph.D. research

735 grant from the French government (Ministère de l'Enseignement Supérieur et de la Recherche).

736 We thank Cécile Taffin for her help with the cryostat. We thank L. Roach and an anonymous

737 reviewer for their insightful comments. Thorough advising from Nicolas Mangold and Stéphane

738 Pochat greatly improved the quality of this article.

739

$740 \quad$ References

741 Arvidson, R.E., and 25 colleagues (2006), Overview of the Spirit Mars Exploration Rover

742 Mission to Gusev Crater: Landing site to Backstay Rock in the Columbia Hills, J. of Geophys.

743 Res., 111, E02S01, doi:10.1029/2005JE002499.

745 Bagnold, R.A. (1954), The physic of blown sand and desert dunes, Dover Publications, 265 p.

747 Berger, G., M.J. Toplis, E. Treguier, C. d'Uston and P. Pinet (2009), Evidence in favor of small

748 amounts of ephemeral and transient water during alteration at Meridiani Planum, Mars, American

749 Mineralogist, 94, 1279-1282.

750

751 Betterton, M.D. (2001), Theory of structure formation in snowfields motivated by penitentes,

752 suncups, and dirt cones, Physical Review E, 63, 056129.

753

754 Bibring, J-P., and 42 colleagues (2004), OMEGA : Observatoire pour la Minéralogie, l'Eau, les

755 Glaces et l'Activité, Eur. Space Agency Spec. Publ. 1240, 37. 
757 Byrne, S. and B.C. Murray (2002), North polar stratigraphy and the paleo-erg of Mars, J. of

758 Geophys. Res., 107, E6, 5044, doi: 10.1029/2001JE001615.

759

760 Byrne, S., M.T. Zuber, G.A. Neumann (2008), Internannual and seasonal behavior of Martian

761 residual ice-cap albedo, Planet. and Sp. Sci., 56, 194-211.

762

763 Calvin, W.M., L.H. Roach, F.P. Seelos, K.D. Seelos, R.O. Green, S.L. Murchie, J.F. Mustard

764 (2009), CRISM Observations of the Northern Martian Latitudes in Summer, J. of Geophys. Res.,

765 114, E00D11, doi:10.1029/2009JE003348.

766

767 Carr, M.H. and J.W. Head (2009), Geologic history of Mars, Earth and Planet. Sci. Lett.,

768 doi:10.1016/j.epsl.2009.06.042.

769

770 Catling, D.C. (1999), A chemical model for evaporites on early Mars: Possible sedimentary

771 tracers of the early climate and implications for exploration, J. of Geophys. Res., 104, 16,453-

$77216,469$.

773

774 Chevrier, V. and P.E. Mathé, (2007), Mineralogy and evolution of the surface of Mars: a review,

775 Planet. and Sp. Sci., 55, 289-314.

776

777 Christensen, P.R., and 26 colleagues (2004), Mineralogy at Meridiani Planum from the Mini-Tes 778 experiment on the Opportunity rover, Science, 306, 1733-1739.

779 
780 Cloutis, E.A., and 11 colleagues (2006), Detection of sulfate minerals using reflectance

781 spectroscopy, Icarus, 184, 121-157.

782

783 Cloutis, E.A., M.A. Craig, R.V. Kruzelecky, W.R. Jamroz, A. Scott, F.C. Hawthorne, S.A.

784 Mertzman (2008), Spectral reflectance properties of minerals exposed to simulated Mars surface

785 conditions, Icarus, 195, 140-168.

786

787 Dupire, C., E. Le Menn, O. Grasset and S. Le Mouélic (2009), In situ infrared studies of water

788 and $\mathrm{CO} 2$ frost between 1 and $5 \mu \mathrm{m}$ : from the grain to the icy surfaces signatures, $40^{\text {th }} \mathrm{LPS}$,

789 Abstract 1242.

790

791 Edgett, K.S., R.M.E. Williams, M.C. Malin, B.A. Cantor, P.C. Thomas (2003), Mars landscape

792 evolution: influence of stratigraphy in the north polar region, Geomorphology, 52, 289-297.

793

794 Fishbaugh, K.E. and J.W. Head III (2000), North polar region of Mars: Topography of circum-

795 polar deposits from Mars Orbiter Laser Altimeter (MOLA) data and evidence for asymmetric

796 retreat of the polar cap, J. of Geophys. Res., 105, 22,455-22,486.

797

798 Fishbaugh, K.E. and J.W. Head III (2005), Origin and characterisitics of the Mars north polar

799 basal unit and implications for polar geologic history, Icarus, 174, 444-474.

800

801 Fishbaugh, K.E., F. Poulet, V. Chevrier, Y. Langevin and J.-P. Bibring (2007), On the origin of

802 gypsum in the Mars north polar region, J. of Geophys. Res., 112, E07002,

803 doi:10.1029/2006JE002862. 
805 Fishbaugh, K.E., C.S. Hvidberg, D. Beaty, S. Clifford, D. Fisher, A. Haldemann, J.W. Head, M.

806 Hecht, M. Koutnik, K. Tanaka, W.J. Ammann (2008), Introduction to the $4^{\text {th }}$ Mars Polar Science 807 and Exploration Conference special issue: Five top questions in Mars polar science, Icarus, 196, $808 \quad 305-317$.

809

810 Fisher, D.A., M.H. Hecht, S.P. Kounaves and D.C. Catling (2010), A perchlorate brine lubricated

811 deformable bed facilitating flow of the north polar cap of Mars: possible mechanism for water

812 table recharging, J. of Geophys. Res., 115, E00E12, doi:10.1029/2009JE003405.

813

814 Fountain, A.G., T.H. Nylen, K.L. MacClune, G.L. Dana (2006), Glacier and mass balances

815 (1993-2001), Taylor Valley, McMurdo Dry Valleys, Antarctica, Journal of Glaciology, 52, no 816178.

817

818 Gendrin, A., N. Mangold, J.-P. Bibring, Y. Langevin, B. Gondet, F. Poulet, G. Bonello, C.

819 Quantin, J. Mustard, R. Arvidson and S. Le Mouélic (2005), Sulfates in Martian layered terrains :

820 the OMEGA/Mars Express view, Science, 307, 1587-1591.

821

822 Green, A.A., M. Berman, P. Switzer, and Craig, M.D. (1988), A transformation for ordering

823 multispectral data in terms of image quality with implications for noise removal: IEEE,

824 Transactions on Geoscience and Remote Sensing, 26, no. 1, p. 65-74. 
826 Halevy, I., and D.P. Schrag (2009), Sulfur dioxide inhibits calcium carbonate precipitation:

827 implications for early Mars and Earth, Geophys. Res. Lett., 36, L23201, doi:10.1029/

828 2009GL040792.

829

830 Hanley, J., V.F. Chevrier, B.L. Davis, T.S. Altheide, A. Francis (2009), Reflectance spectra of

831 low-temperature chloride and perchlorate hydrates and thier relevance to the martian surface, The

832 New Martian Chemistry Workshop, abstract 8010.

833

834 Hanley, J., V.F. Chevrier, B.L. Davis, T.S. Altheide, A. Francis (2010), Reflectance spectra of

835 low-temperature chloride and perchlorate hydrates and their relevance to the martian surface, $41^{\text {st }}$

836 Lunar and Planetary Science Conference, Abstract 1953.

837

838 Hayward, R.K., K.F. Mullins, L.K. Fenton, T.M. Hare, T.N. Titus, M.C. Bourke, A. Colaprete

839 and P.R. Christensen (2007), Mars Global Digital Dune Database and initial science results, J. of

840 Geophys. Res., 112, E11007, doi:10.1029/2007JE002943.

841

842 Hecht, M.H., and 13 colleagues (2009), Detection of Perchlorate and the Soluble Chemistry of

843 Martian Soil at the Phoenix Lander Site, Science, 325, 64, doi: 10.1126/science.1172466.

845 Herkenhoff, K.E., S. Byrne, P.S. Russel, K.E. Fishbaugh, A.S. McEwen (2007), Meter-scale

846 morphology of the North Polar Region of Mars, Science, 317, 1711-1715, doi:

$847 \quad 10.1126 /$ science.1143544.

848 
849 Herkenhoff, K.E., A.R. Vasada (1999), Dark material in the polar layered deposits and dunes on

850 Mars, J. of Geophys. Res., 104, 16,487-16,500.

851

852 Hoffman, M.J., A.G. Fountain and G.E. Liston (2008), Surface energy balance and melt

853 thresholds over 11 years at Taylor Glacier, Antarctica, J. of Geophys. Res., 113, F04014, doi:

854 10.1029/2008JF001029.

855

856 Horgan, B.H., J.F. Bell III, E.Z. Noe Dobrea, E.A. Cloutis, D.T. Bailey, M.A. Craig, L.H. Roach,

857 and J. F. Mustard (2009), Distribution of hydrated minerals on the north polar region of Mars, J.

858 of Geophys. Res., 114, E01005, doi:10.1029/2008JE003187,

859

860 Horgan, B.H. and J.F. Bell III (2009), Insights from ferrous mineralogy into the transport of

861 martian north polar materials, 40 ${ }^{\text {th }}$ LPSC, Abstract 2457.

862

863 Howard, A.D. (2000), The role of eolian processes in forming surface features of the Martian

864 Polar Layered Deposits, Icarus, 144, 267-288, doi: 10.1006/icar.1999.6305.

865

866 Howard, A.D., J.A. Cutts, K.R. Blasius (1982), Stratigraphic relationships within Martian polar

867 cap deposits, Icarus, 50, 161-215.

868

869 Huguenin, R.L. and J.L. Jones (1986), Intelligent information extraction from reflectance spectra:

870 absorption band positions, J. of Geophys. Res., 91, 9585-9598.

871 
872 Ivanov, A.B. and D.O. Muhleman (2000), The roles of sublimation for the formation of the

873 northern ice cap: results from the Mars Orbiter Laser Altimeter, Icarus, 144, 436-448.

874

875 Iizuka, Y., T. Hondoh, Y. Fujii (2006), $\mathrm{Na}_{2} \mathrm{SO}_{4}$ and $\mathrm{MgSO}_{4}$ salts during the Holocene period

876 derived by high-resolution depth analysis of a Dome Fuji ice core, Journal of Glaciology, 52, No. 877176.

878

879 Iizuka, Y., S. Horikawa, T. Sakurai, S. Johnson, D. Dahl-Jensen, J.P. Steffensen, and T. Hondoh 880 (2008), A relationship between ion balance and the chemical compounds of salt inclusions found 881 in the Greenland Ice Core Project and Dome Fuji ice cores, J. of Geophys. Res., 113, D07303, 882 doi:10.1029/2007JD009018.

884 Kieffer, H.H., S.C. Chase, T.Z. Martin, E.D. Miner and F. Don Palluconi (1976), Martian North 885 Pole summer temperature: dirty water ice, Science, 194, 1341-1344.

887 Langevin, Y., F. Poulet, J.-P. Bibring, B. Schmitt, S. Douté, B. Gondet (2005a), Summer 888 evolution of the North Polar Cap of Mars as observed by OMEGA/Mars Express, Science, 307, $889 \quad 1581-1584$

891 Langevin, Y., F. Poulet, J.-P. Bibring, J.-P. Bibring and B. Gondet (2005b), Sulfates in the North 892 Polar Region of Mars detected by OMEGA/Mars Express, Science, 307, 1584-1586.

894 Le Deit, L., S. Le Mouélic, D. Mège, O. Bourgeois, J.-P. Combe, C. Sotin, A. Gendrin, E. 895 Hauber, N. Mangold and J.-P. Bibring (2008), Ferric oxides in East Candor Chasma, Valles 
896

897

898

899

900 901 carbonate sediments, Optics Express, 1573.

902

903

904

905

906

907

908

909

910

911

912

913

914

915

916

917

918 McKee, E.D. (1979), Introduction to a study of global sand seas, in A study of global sand seas, 919

Marineris (Mars) inferred from analysis of OMEGA/Mars Express data: identification and geological interpretation, J. of Geophys. Res., 113, Issue E7, doi:10.1029/2007JE002950.

Louchard, E.M., R.P. Reid, C.F. Stephens, C.O. Davis, R.A. Leathers, T.V. Downes, R. Maffione (2002), Derivative analysis of absorption features in hyperspectral remote sensing data of

Malin, M.C., and 13 colleagues (2007), Context Camera Investigation on board the Mars Reconnaissance Orbiter, J. of Geophys. Res., 112, E05S04, doi: 10.1029/2006JE002808.

Massé, M., S. Le Mouélic, O. Bourgeois, J.-P. Combe, L. Le Deit, C. Sotin, J.-P. Bibring, B.

Gondet and Y. Langevin (2008), Mineralogical composition, structure, morphology, and geological history of Aram Chaos crater fill on Mars derived from OMEGA Mars Express data, J. of Geophys. Res., 113, E12006, doi:10.1029/2008JE003131.

McEwen, A.S., and 14 colleagues (2007), Mars Reconnaissance Orbiter's High Resolution Imaging Science Experiment (HiRISE), J. of Geophys. Res., 112, E05S02, doi:10.1029/2005JE002605.

McGuire, P.C., and 14 colleagues (2009), An improvement to the volcano-scan algorithm for atmospheric correction of CRISM and OMEGA spectral data, Planet. Sp. Sci., 57, 809-815.
U.S. Geological Survey Professional Paper, 400p. 
921 Milkovich, S.M. and J.W. Head (2006), Surface textures of Mars' north polar layered deposits: A

922 framework for interpretation and future exploration, Mars 2, 21-45.

923

924 Mölg T., D.R. Hardy and G. Kaser (2003), Solar-radiation-maintained glacier recession on

925 Kilimanjaro drawn from combined ice-radiation geometry modelling, J. of Geophys. Res., 108,

926 D23, 4731, doi:10.1029/2003JD003546.

927

928 Mölg T.and D.R. Hardy (2004), Ablation and associated energy balance of a horizontal glacier

929 surface on Kilimanjaro, J. of Geophys. Res., 109, D16104, doi: 10.1029/2003JD004338.

930

931 Mölg T., N.J. Cullen, D.R. Hardy, G.Kaser and L. Klok (2008), Mass balance of a slope glacier

932 on Kilimanjaro and its sensitivity to climate, International Journal of Climatology, 28, 881-892.

933

934 Morris, R.V., D.C. Golden, D.W. Ming, T.G. Graff, R.E. Arvidson, S.M. Wiseman, K.A.

935 Lichtenberg and S. Cull (2009), Visible and near-IR reflectance spectra for smectite, sulfate and

936 perchlorate under dry conditions for interpretation of martian surface mineralogy, $40^{\text {th }}$ LPSC,

937 Abstract 2317.

938

939 Murchie, S.R., and 49 colleagues (2007), Compact reconnaissance imaging spectrometer for

940 Mars (CRISM) on Mars Reconnaissance Orbiter (MRO), J. of Geophys. Res., 112(E5), E05S03,

941 doi:10.1029/2006JE002682.

942 
943 Niles, P. and J. Michalski (2009), Meridiani Planum sediments on Mars formed through

944 weathering in massive ice deposits, Nature Geoscience, 2, 215 - 220.

945

946 Ohno, H., M. Igarashi, and T. Hondoh (2006), Characteristics of salt inclusions in polar ice from

947 Dome Fuji, East Antartica, Geophys. Res. Lett., 113, L08501, doi: 10.1029/2006GL025774.

948

949 Parente, M. (2008), A new approach to denoising CRISM images, Lunar and Planetary Science

$950 \quad$ XXXIX, Abstract 2528.

951

952 Pelkey, S.M., J.F. Mustard, S. Murchie, R.T. Clancy, M. Wolff, M. Smith, R. Milliken, J.-P.

953 Bibring, A. Gendrin, F. Poulet, Y. Langevin and B. Gondet (2007), CRISM multispectral

954 summary products: Parameterizing mineral diversity on Mars from reflectance, J. of Geophys.

955 Res., 112, E08S14, doi:10.1029/2006JE002831.

956

957 Picardi, G ., and 33 colleagues (2005), Radar sounding of the subsurface of Mars, Science, 310,

$958 \quad 1925-1928$.

959

960 Phillips, R.J., and 26 colleagues (2008), Mars north polar deposits: stratigraphy, age, and

961 geodynamical response, Science, 320, 1182-1185.

962

963 Poulet, F., Y. Langevin, G. Boubin, D. Jouglet, J.-P. Bibring and B. Gondet (2008), Spectral

964 variability of the Martian high latitude surfaces, Geophys. Res. Lett., 35, L20201,

965 doi:10.1029/2008GL035450.

966 
967 Putzig, N.E., R.J. Phillips, B.A. Campbell, J.W. Holt, J.J. Plaut, L.M. Carter, A.F. Egan, F.

968 Bernardini, A. Saefaeinili, R. Seu (2009), Subsurface structure of Planum Boreum from Mars

969 Reconnaissance Orbiter shallow radar soundings, Icarus, doi: 10.1016/j.icarus.2009.07.034.

970

971 Rhodes, J.J., R.L. Armstrong, S.G. Warren (1987), Mode of formation of "ablation hollows"

972 controlled by dirt content of snow, Journal of Glaciology, 33, 135-139.

973

974 Roach, L.H., and 16 colleagues (2007), CRISM spectral signatures of the North polar gypsum

975 dunes, LPSC XXXVII, abstract 1970.

976

977 Roach, L.H., J.F. Mustard, S.L. Murchie, J.-P. Bibring, F. Forget, K.W. Lewis, O. Aharonson, M.

978 Vincendon and J.L. Bishop (2009), Testing evidence of recent hydration state change in sulfates

979 on Mars, J. of Geophys. Res., 114, E00D02, doi: 10.1029/2008JE003245.

980

981 Rodriguez, J.A.P., K.L. Tanaka, Y. Langevin, M. Bourke, J. Kargel, P. Christensen and S. Sasaki

982 (2007), Recent aeolian erosion and deposition in the north polar plateau of Mars, Mars 3, 29-41.

983

984 Rouchy, J.-M. and Blanc-Valleron M.-M. (2006), Les évaporites : Matériaux singuliers, milieux

985 extrêmes, Vuibert, 190 p.

986

987 Smith, D.E., and 21 colleagues (2001a), Mars Orbiter Laser Altimeter (MOLA): Experiment

988 summary after the first year of global mapping of Mars, J. of Geophys. Res., 106, 23689-23722.

989 
990 Smith, D.E., M.T. Zuber, G.A. Neumann (2001b), Seasonal variations of snow depth on Mars,

991 Science, 294, no. 5549, 2141-2146.

992

993 Squyres, S.W., and 15 colleagues (2006), Rocks of the Columbia Hills,, J. of Geophys. Res., 111, 994 E02S11, doi:10.1029/2005JE002562.

995

996 Szynkiewicz, A., R.C. Ewing, C.H. Moore, M. Glamoclija, D. Bustos, L.M. Pratt (2010), Origin

997 of terrestrial gypsum dunes-Implications for Martian gypsum-rich dunes of Olympia Undae,

998 Geomorphology, in press, DOI: 10.1016/j.geomorph.2009.02.017.

999

1000 Talsky, G. (1994), Derivative Spectrophotometry, low and high order, VCH Publishers.

1001

1002 Tanaka, K.L., J.A.P. Rodriguez, JA. Skinner, M.C. Bourke, C.M. Fortezzo, K.E. Herkenhoff, E.J.

1003 Kolb, C.H. Okubo (2008), North polar region of Mars: Advances in stratigraphy, structure, and 1004 erosional modification, Icarus, 196, 318-358.

1005

1006 Tanaka, K.L. and R.K. Hayward (2008), Mars' North circum-polar dunes: distribution, sources,

1007 and migration history, Planetary Dunes Workshop: A record of climate change, abstract 7012.

1008

1009 Thomas, P. and C. Weitz (1989), Sand dune materials and polar layered deposits on Mars, Icarus, $1010 \quad 81,185-215$.

1011

1012 Tsai, F., and W. Philpot (1998), Derivative analysis of hyperspectral data, Remote Sensing of 1013 Environment, 66(1), 41-51. 
1015 Tsoar, H., R. Greeley, A.R. Peterfreund (1979), Mars: the north polar sand sea and related wind 1016 patterns, J. of Geophys. Res., 84, 8167-8180.

1017

1018 Verpoorter, C., V. Carrère, M. Robin (2007), Retrieval of physical properties of mudflat

1019 sediments from hyperspectral data using the modified gaussian model and spectral curve fitting,

1020 Proceedings 5th EARSeL Workshop on Imaging Spectroscopy.

1021

1022 Verpoorter, C. (2009), Teledetection hyperspectrale et cartographie des facies sedimentaires en 1023 zone intertidale: application a la baie de Bourgneuf, $\mathrm{PhD}$, University of nantes, 423p.

1025 Verpoorter, C., J.P., Combe and V., Carrere (2010), Development of an automatic Spectral

1026 Derivative - Modified Gaussian Model (SD-MGM) for the analysis of bio-geophysical properties 1027 of mudflat sediments from hyperspectral data, submitted in Remote Sensing of Environment.

1029 Warner, N.H. and J.D. Farmer (2008), Importance of Aeolian processes in the origin of the north 1030 polar chasmata, Mars, Icarus, 196, 368-384.

1031

1032 Wray, J.J., S.L. Murchie, S.W. Squyres, F.P. Seelos and L.L. Tornabene (2009), Diverse aqueous 1033 environments on ancient Mars revealed in the southern highlands, Geology, 37, 1043-1046.

1035 Zuber, M., and 20 colleagues (1998), Observations of the north polar region of Mars from the 1036 Mars Orbiter Laser Altimeter. Science, 282, 2053-2060. 


\section{Figure captions}

1039 Figure 1: a) Topographic map of the North Polar Cap (shaded and colored relief image computed 1040 from the MOLA DEM at $\sim 512 \mathrm{~m} / \mathrm{pixel}$ overlain on a MOC mosaic at $\sim 221 \mathrm{~m} / \mathrm{pixel}$ ). The orange

1041 dotted line represents the extension of the Basal Unit (BU) inferred from radar soundings by

1042 Putzig et al. [2009]. b) Map of gypsum concentration in the Circum-Polar Dune Field, computed

1043 from 11 OMEGA observations by Langevin et al. [2005b]. The North Polar Cap appears in white

1044 and grey, whereas the Circum-Polar Dune Field appears in black. Colors indicate the depth of the

$10451.927 \mu \mathrm{m}$ absorption band, interpreted as a proxy for the distribution of gypsum. c) Interpretative

1046 cross-section of the North Polar Cap based on SHARAD radargrams [Putzig et al., 2009]. The

1047 dotted line indicates the top of the Vastitas Borealis Formation (VBF), as interpreted from scarce

1048 radar returns.

1050 Figure 2: Context map of the study area (shaded and colored relief image computed from the

1051 MOLA DEM at $\sim 512 \mathrm{~m} /$ pixel overlain on a CTX mosaic; location indicated by a grey box in

1052 Figure 1). Topographic contours drawn at $200 \mathrm{~m}$ intervals underline the interior spiral troughs

1053 and the marginal arcuate scarps. The Circum-Polar Dune Field appears as a low-albedo unit,

1054 whereas ice appears as light outcrops. The study area (red box) encompasses the surface of the

1055 North Polar Cap, two spiral troughs, two arcuate scarps and a portion of the Circum-Polar Dune

1056 Field. The orange dotted line represents the extension of the Basal Unit (BU) inferred from radar

1057 soundings by Putzig et al. [2009].

1058

1059 Figure 3: Structure and morphology of the study area. a) CTX image

1060 P01_001593_2635_XI_83N241W (location indicated by a red box on Figure 2). b) Interpretative 
1061 sketch-map of Figure 3a. The interval of MOLA elevation contours is 100m. c) Close-up view of

1062 the northernmost arcuate scarp, showing the NPLD in its upper part, the BU in its lower part and

1063 superficial dark streamers extending from its base towards the associated dune field (location

1064 indicated by a black box on Figure 3a). d) Interpretative cross-section of the study area (location

1065 on Figure 3a and b). The topographic profile is based on MOLA DTM.

1066

1067 Figure 4: a) Sublimation landforms observed on a dissected packet of sediment-rich ice layers in 1068 the NPLD (Portion of HiRISE image PSP_009267_2640, location indicated by a black box in

1069 Figure 3a). The extent of the superficial ablation till released by sublimation of the packet of ice 1070 layers is delineated by the white dotted line. b) Close-up view on sublimation till and polygonal 1071 ablation hollows at the surface of the packet of ice layers (location indicated by the white box in 1072 Figure 4a). c) Example of terrestrial ablation hollows with concentration of ablation till on ridges 1073 at the surface of the Vatnajökull glacier in Iceland $(20 \mathrm{~cm}$ long hammer for scale) (photo M.

1074 Massé). d) Interpretative block diagram illustrating the internal structure of the packet of ice 1075 layers and the surface sublimation landforms produced by downward ablation of the ice layers.

1078 Figure 5: Laboratory spectra of experimental water ice - gypsum mixtures acquired at $150 \mathrm{~K}$ and 10797 mbar. Grey and black dotted vertical bars underline spectral features attributed to water ice and 1080 gypsum respectively.

1082 Figure 6: First order $\left(\mathrm{R}^{\prime}(\mathrm{x})\right)$ and second order $\left(\mathrm{R}^{\prime \prime}(\mathrm{x})\right)$ derivatives of a portion of a CRISM 1083 spectrum $(\mathrm{R}(\mathrm{x}))$. 
1085 Figure 7: Distribution of absorption bands detected by the spectral derivative method in the

1086 CRISM cube hrl0000330c. The most geologically plausible mineralogical interpretation is

1087 indicated above each frequency peak.

1088

Figure 8: Representative spectra of various morphological units of the study area. The central

1090 image is a color composition (R: $2.5295 \mu \mathrm{m}, \mathrm{V}: 1.5066 \mu \mathrm{m}, \mathrm{B}: 1.0800 \mu \mathrm{m})$ of the study area

1091 computed from CRISM cube hrl0000330c (location indicated by a grey box on Figure 2). Clean

1092 ice layers appear in blue, sediment-rich ice layers appear in white, superficial sublimation tills

1093 appear in various tones ranging from pale to medium brown and dunes appear in dark brown.

1094 Raw (grey) and denoised (black) spectra derived from this CRISM cube are shown to the left and

1095 right of the image. The reflectance values are given for the denoised spectra. For clarity, each raw

1096 spectrum is offset by a constant reflectance value with respect to the corresponding denoised

1097 spectrum. Grey and black dotted vertical bars underline spectral features attributed to ice and

1098 sediment respectively. To decrease the contribution of noise on the displayed spectra, these have

1099 been averaged over boxes (shown in the image) comprising several pixels located on the same

1100 morphological unit. All the spectra have been masked between 1.97 and $2.08 \mu \mathrm{m}$ because the

1101 atmospheric correction fails in this wavelength range.

1103 Figure 9: Distribution of ice, gypsum and other hydrated minerals in the study area, computed

1104 from the CRISM cube hrl0000330c. a) Map of the spectral criterion BD(1.50). b) Map of the

1105 spectral criterion $\mathrm{BD}(1.934)$. c) to j) Maps of selected absorption bands detected by the spectral

1106 derivative method. On c) to j), pixels where the spectrum meets a local minimum at the displayed

1107 wavelength are colored. Colors represent the number of pixels ( 1 to 9 pixels from blue to red)

1108 where this minimum is detected in a moving kernel of $3 \times 3$ pixels. 
1110 Figure 10: Zooms on the CTX image P01_001593_2635_XI_83N241W (location indicated on

1111 Figure 9a) and on maps of absorption bands detected by the spectral derivative method (Figure

1112 9), showing the concentration of gypsum in a) to c) sublimation tills on the dissected packet of

1113 the NPLD ice layers and in d) to f) arcuate scarp and dunes.

1114

1115 Figure 11: Comparison of (denoised) CRISM and (raw) OMEGA spectra acquired on superficial

1116 accumulations of dark sediment in the study area (location indicated on Figure 8). To ensure

1117 consistency of spatial coverage between CRISM and OMEGA data, the displayed CRISM spectra

1118 have been averaged over spatial boxes corresponding to the ground coverage of OMEGA pixels.

1119 Grey and black dotted vertical lines underline spectral features attributed to ice and sediment

1120 respectively.

1121

1122 Figure 12: Regional distribution of ice, gypsum and other hydrated minerals around the study

1123 area (shown by the white box in a), computed from the OMEGA cube ORB1056_2. a) Map of

1124 the spectral criterion $\mathrm{BD}(1.50)$. b) Map of the spectral criterion $\mathrm{BD}(1.934)$. c) to g) Maps of

1125 selected absorption bands detected by the spectral derivative method. On c) to g), pixels where

1126 the spectrum meets a local minimum at the displayed wavelength are colored. Colors represent

1127 the number of pixels ( 1 to 9 pixels from blue to red) where this minimum is detected in a moving

1128 kernel of $3 \times 3$ pixels. h) Location of the OMEGA cube indicated on a shaded and colored relief

1129 image computed from the MOLA DEM at $\sim 256 \mathrm{~m} /$ pixel.

1130

1131 Figure 13: Interpretative scenario for the formation of gypsum in the North Polar Cap. 

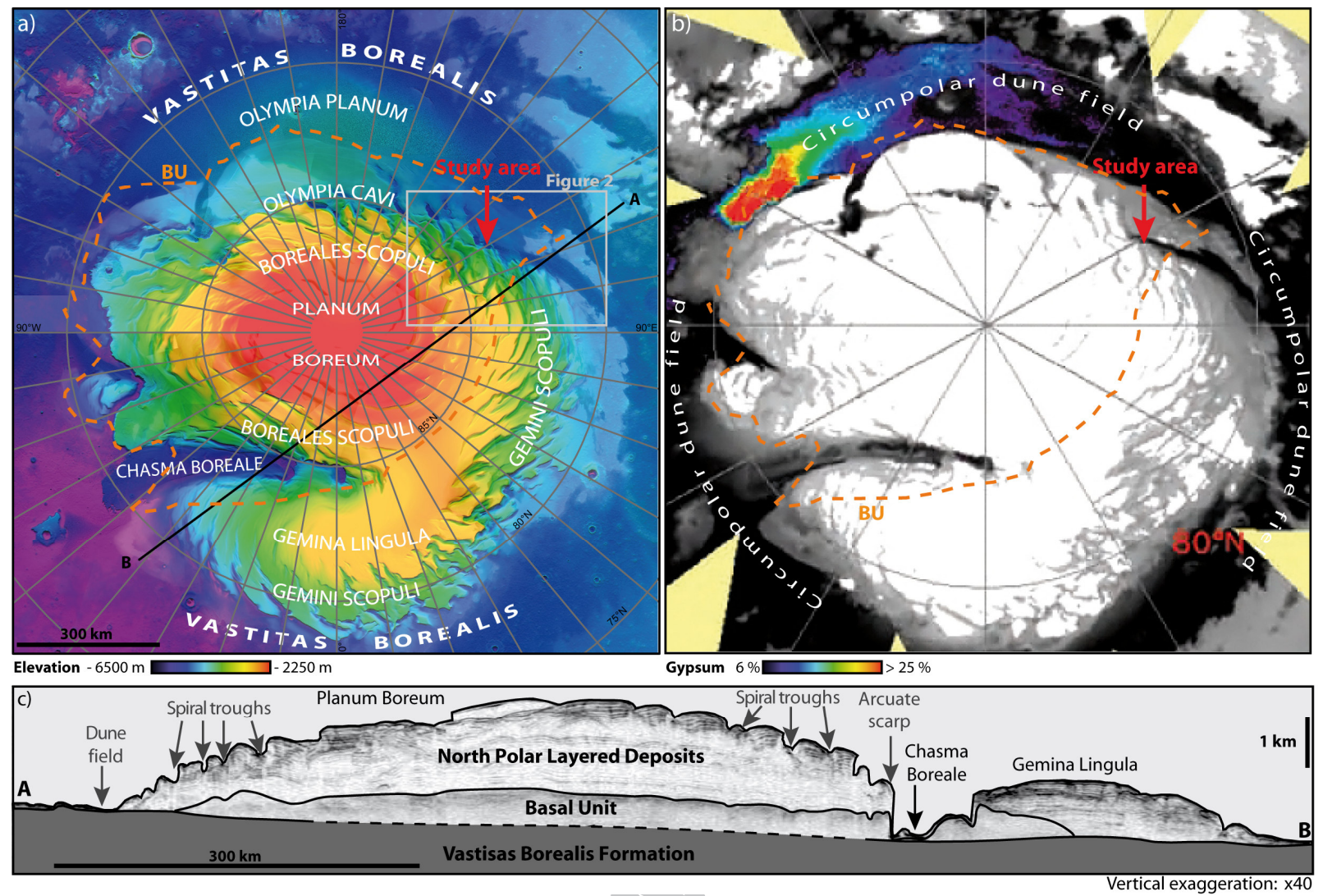

1132 


\section{ACCEPTED MANUSCRIPT}

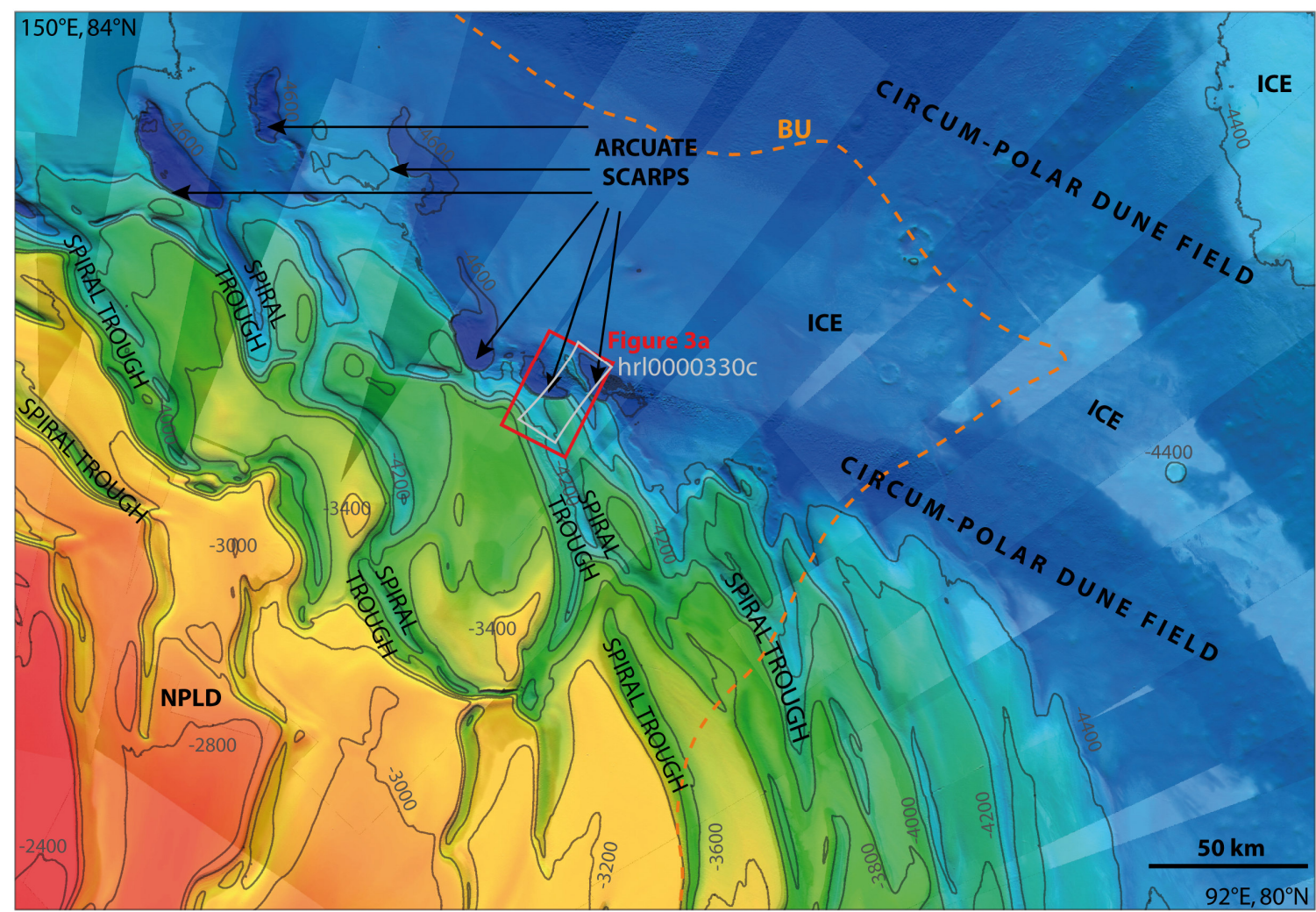

1133 

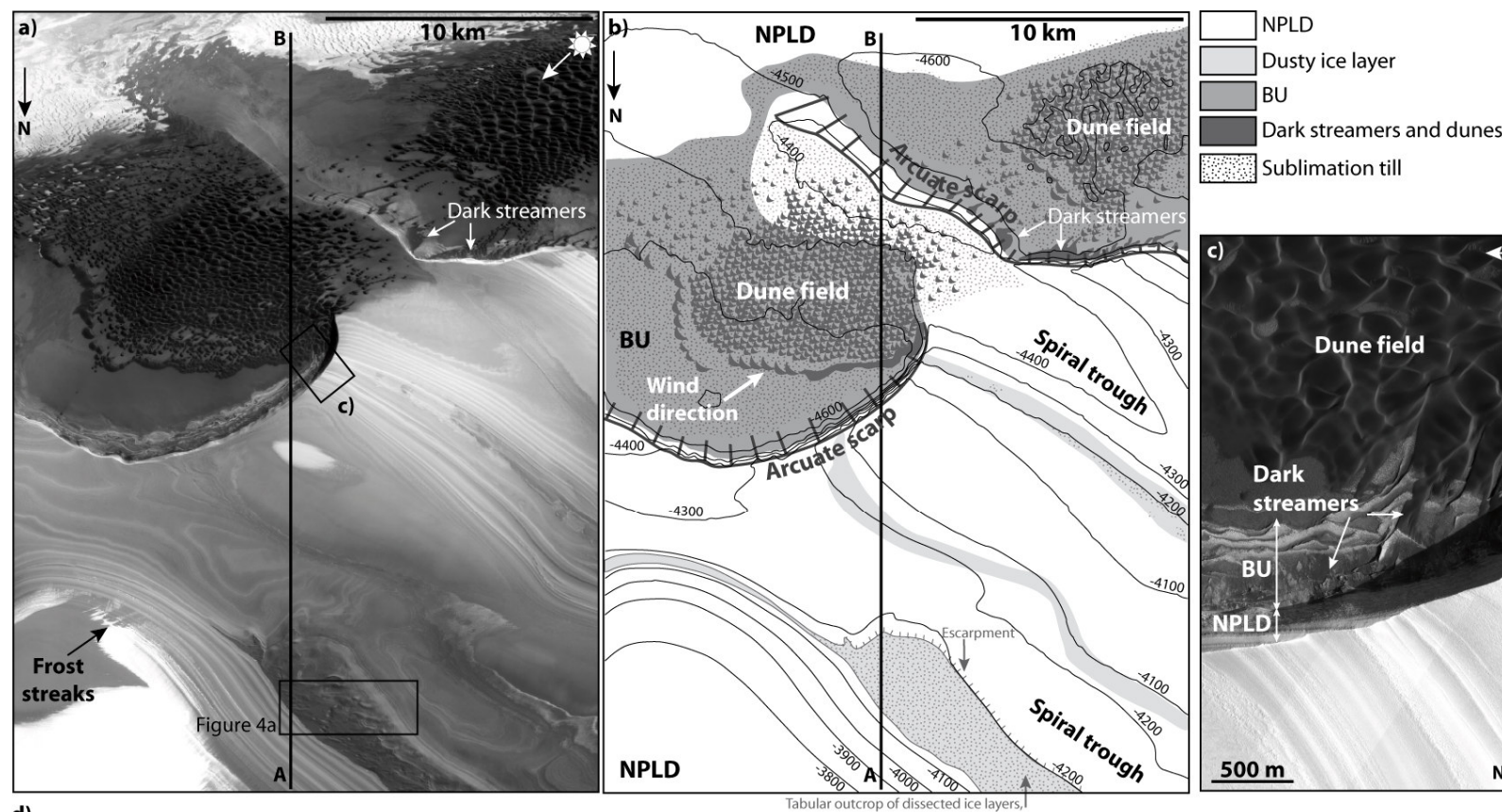

d)

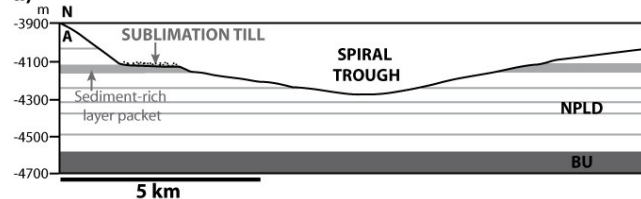

ARCUATE SCARP

bular outcrop of dissected ice layers.

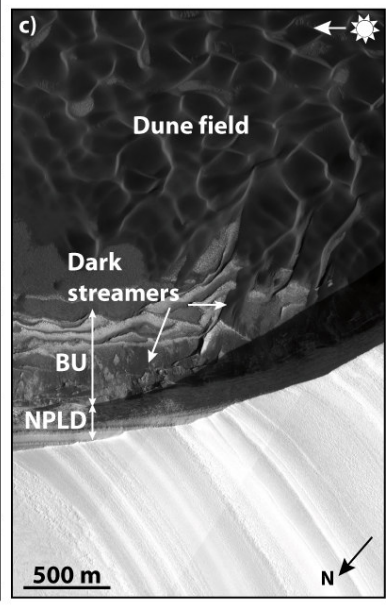

1134

$5 \mathrm{~km}$ 


\section{ACCEPTED MANUSCRIPT}

Tabular outcrop of dissected ice layers, Erosional covered by superficial sediment escarpment
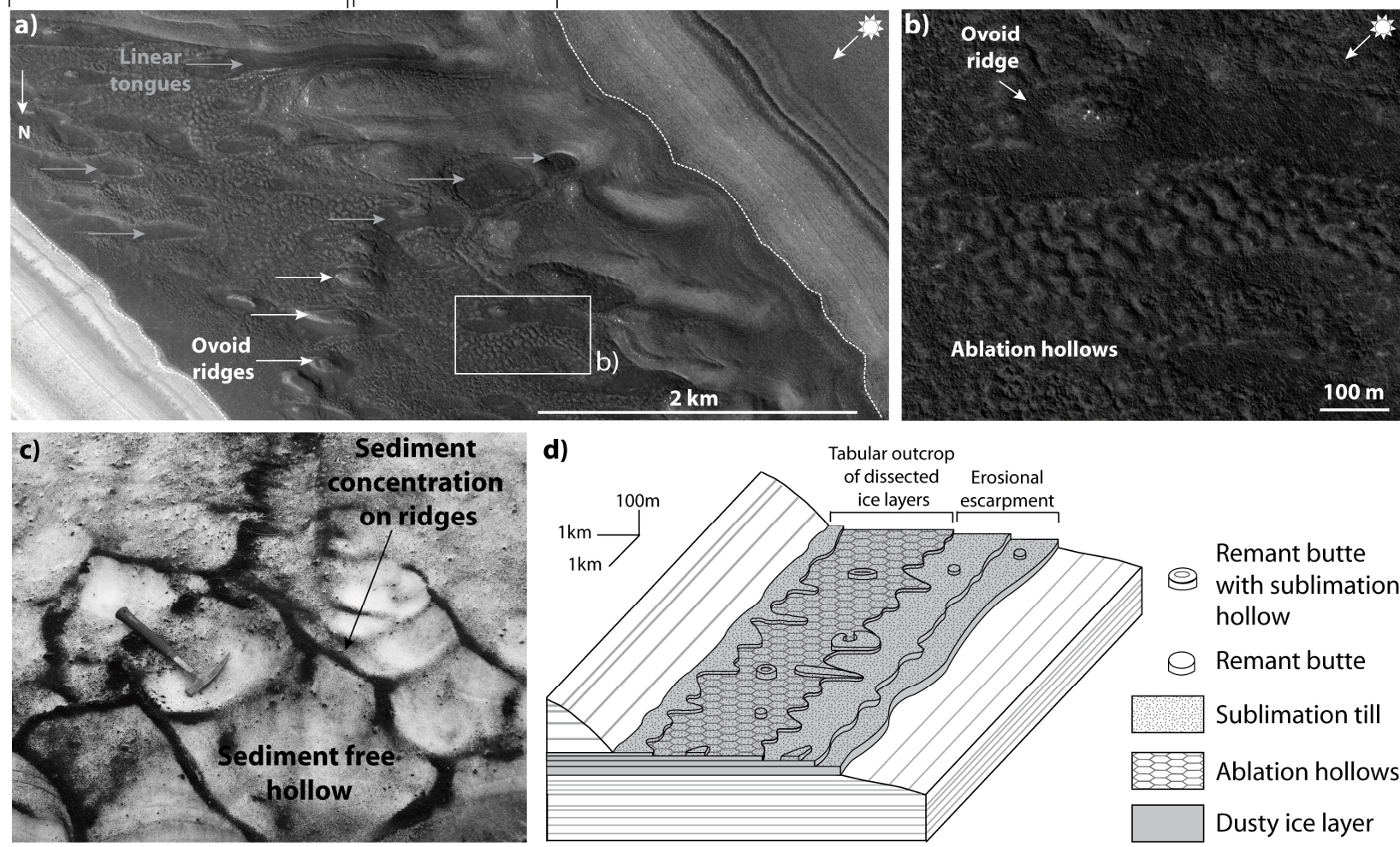

d) Tabular outcrop

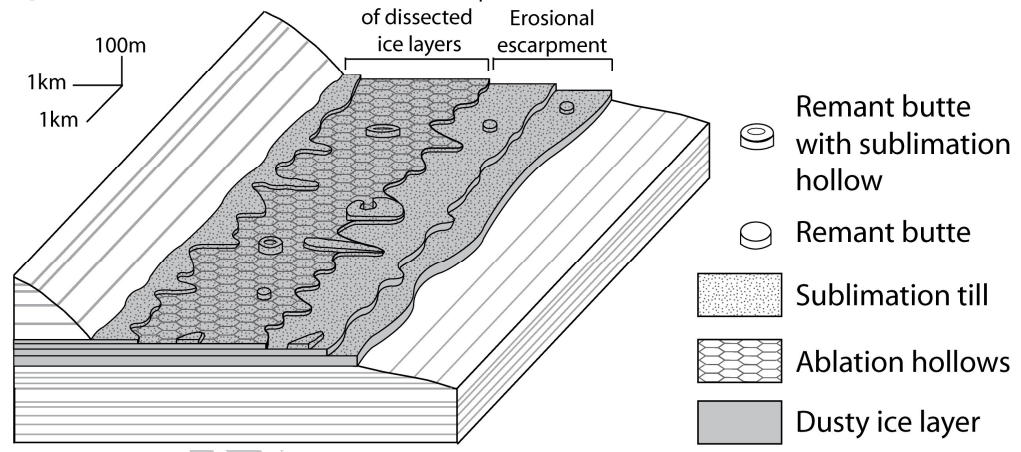




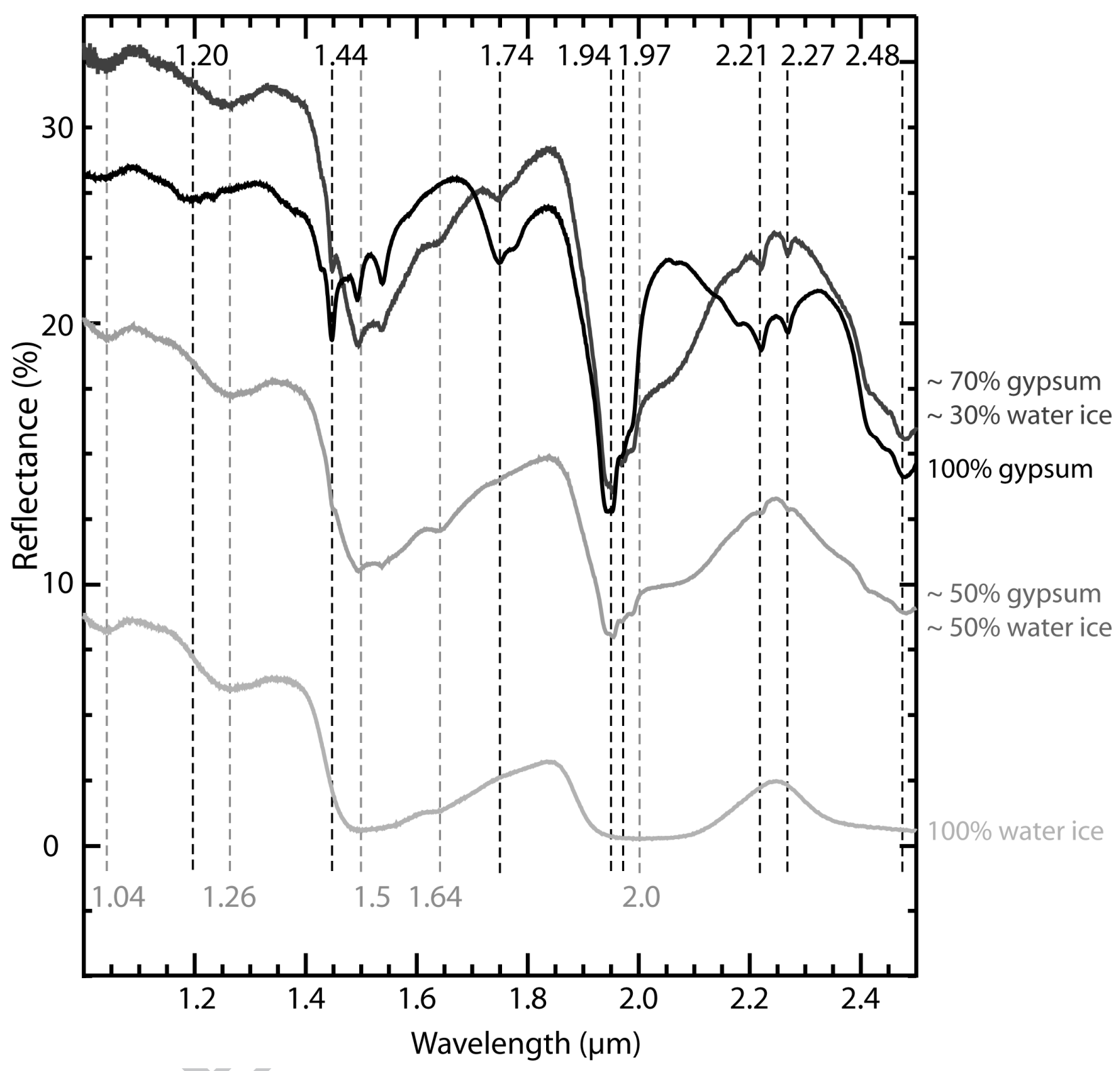

1136 


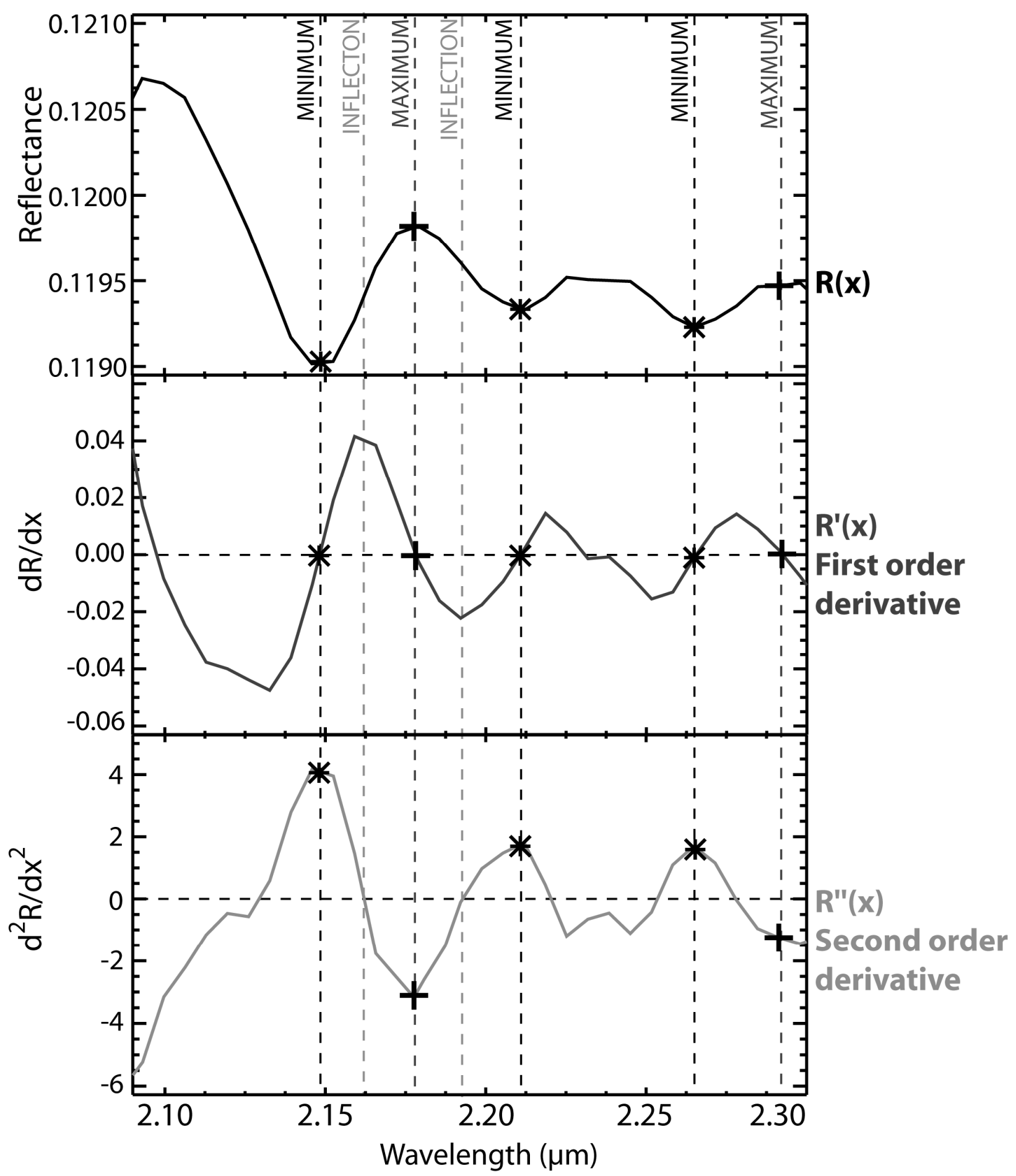




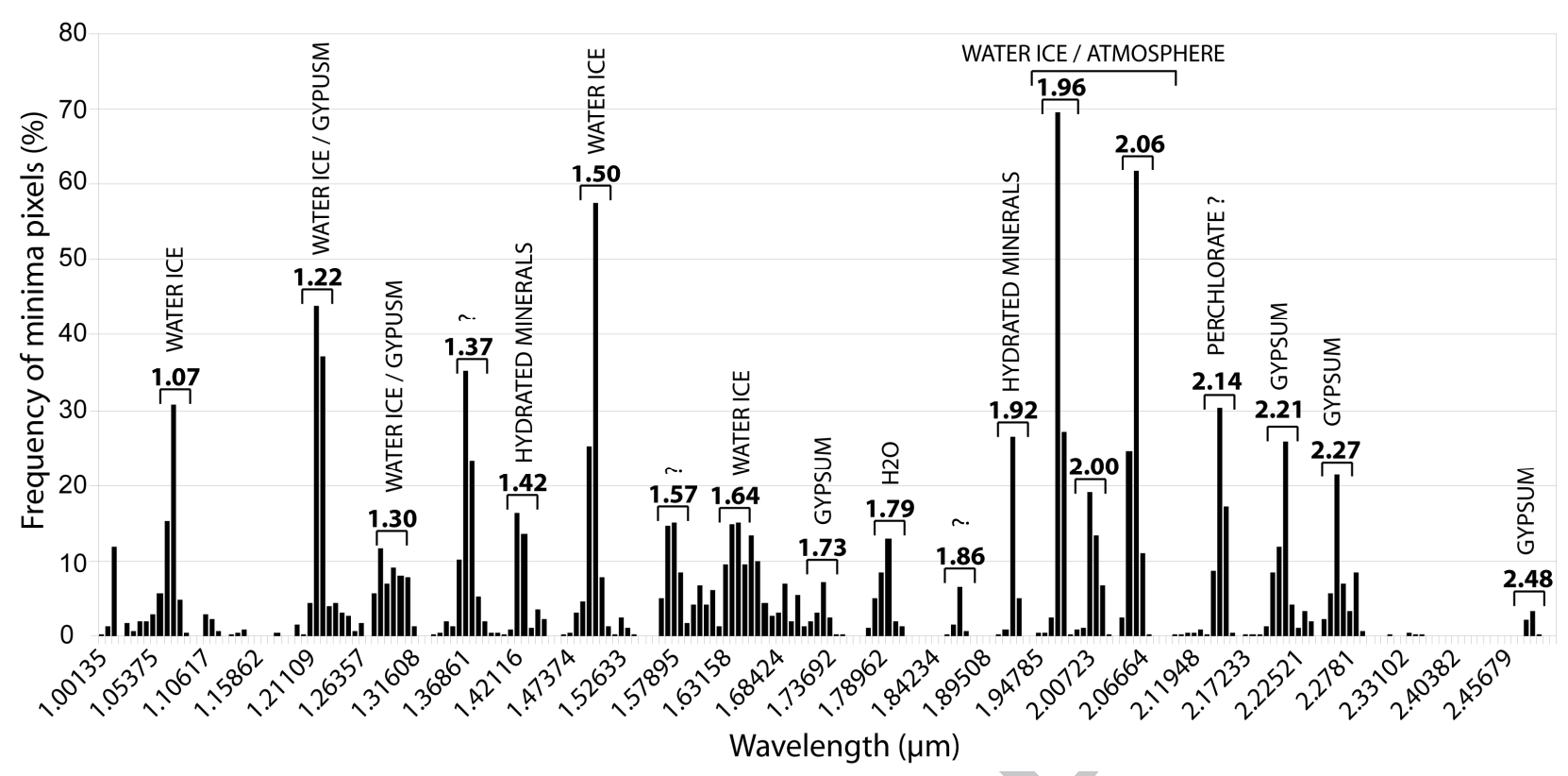


$\begin{array}{llll}2.0 & 2.21 & 2.27\end{array}$

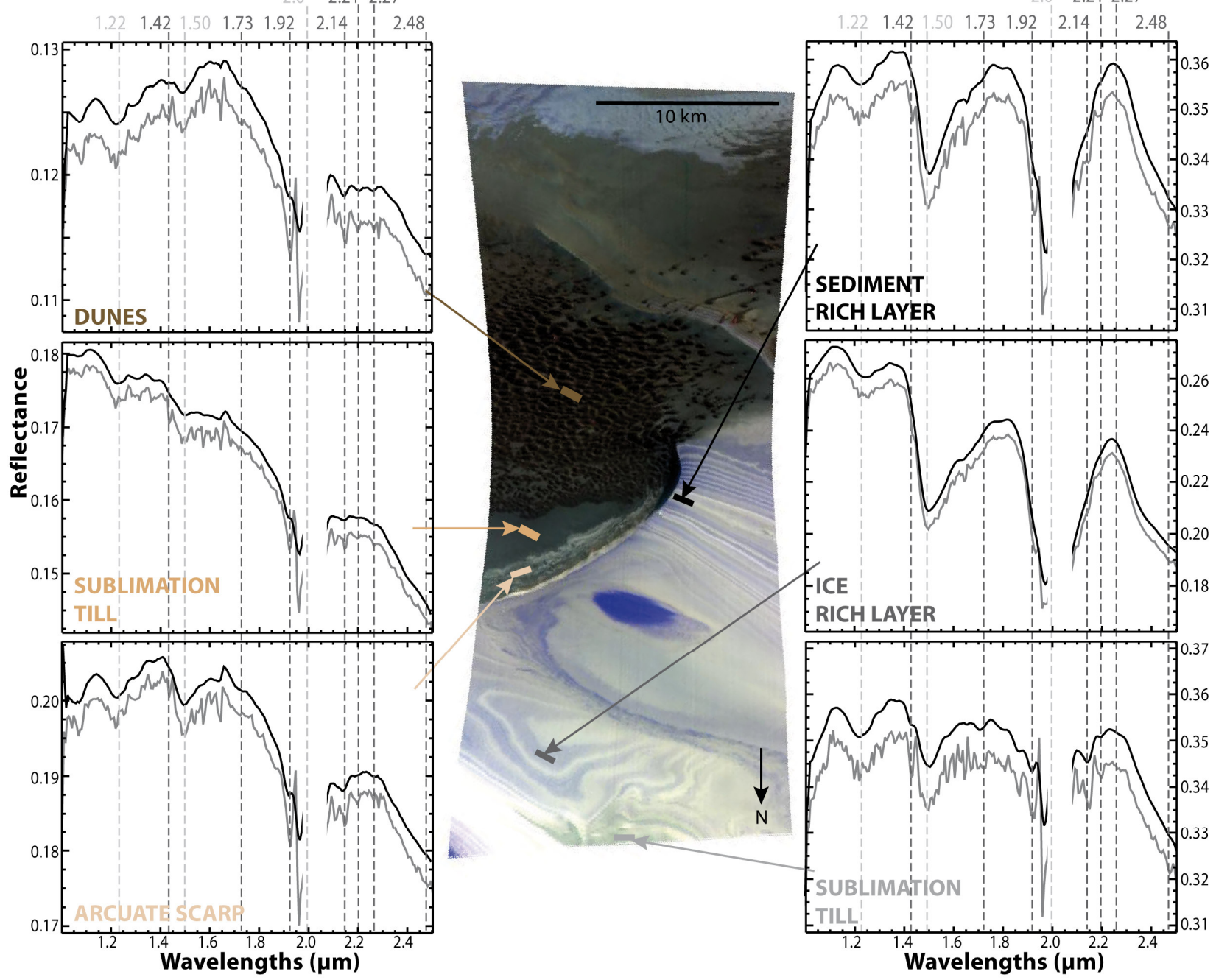

1139 

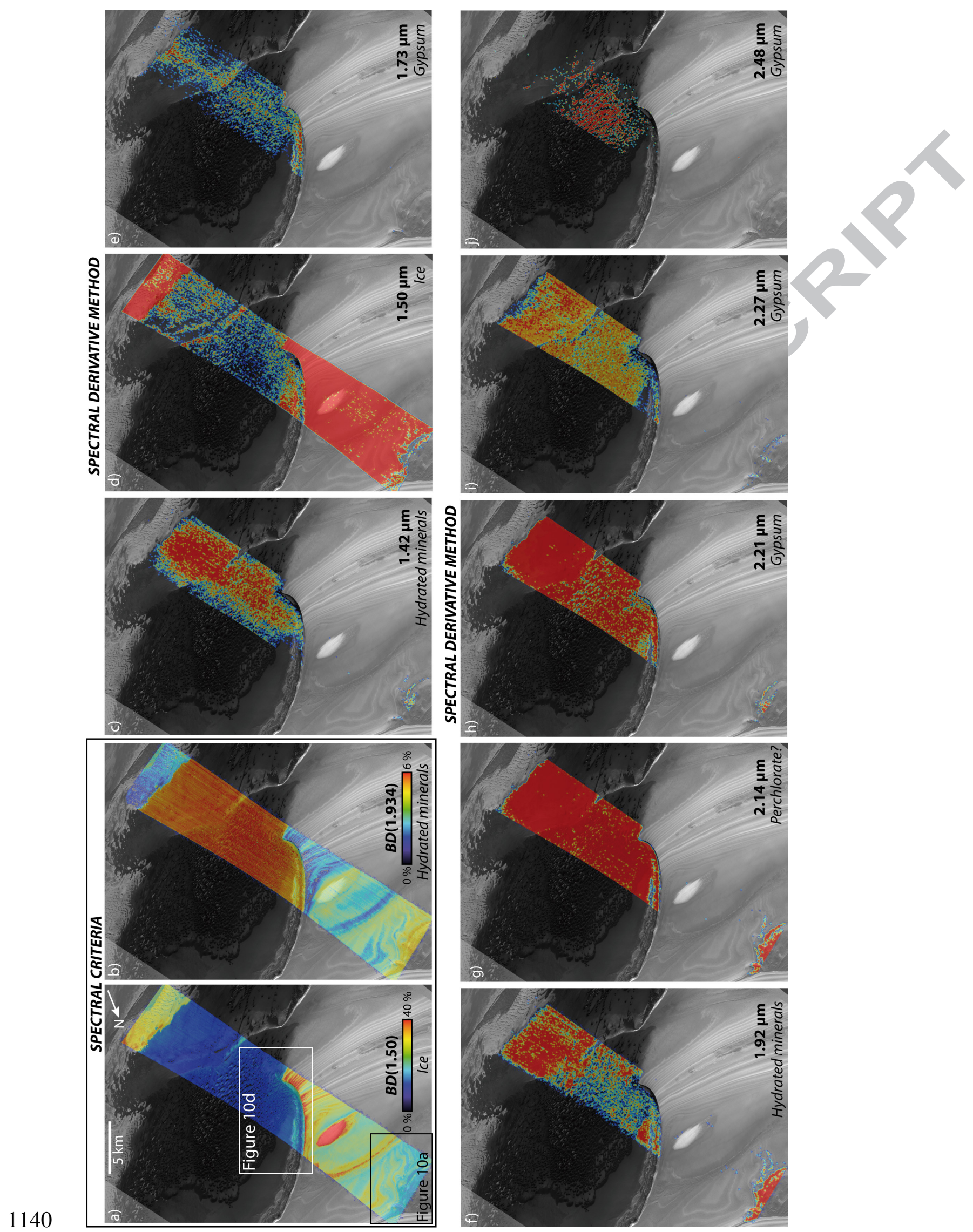


\section{ACCEPTED MANUSCRIPT}
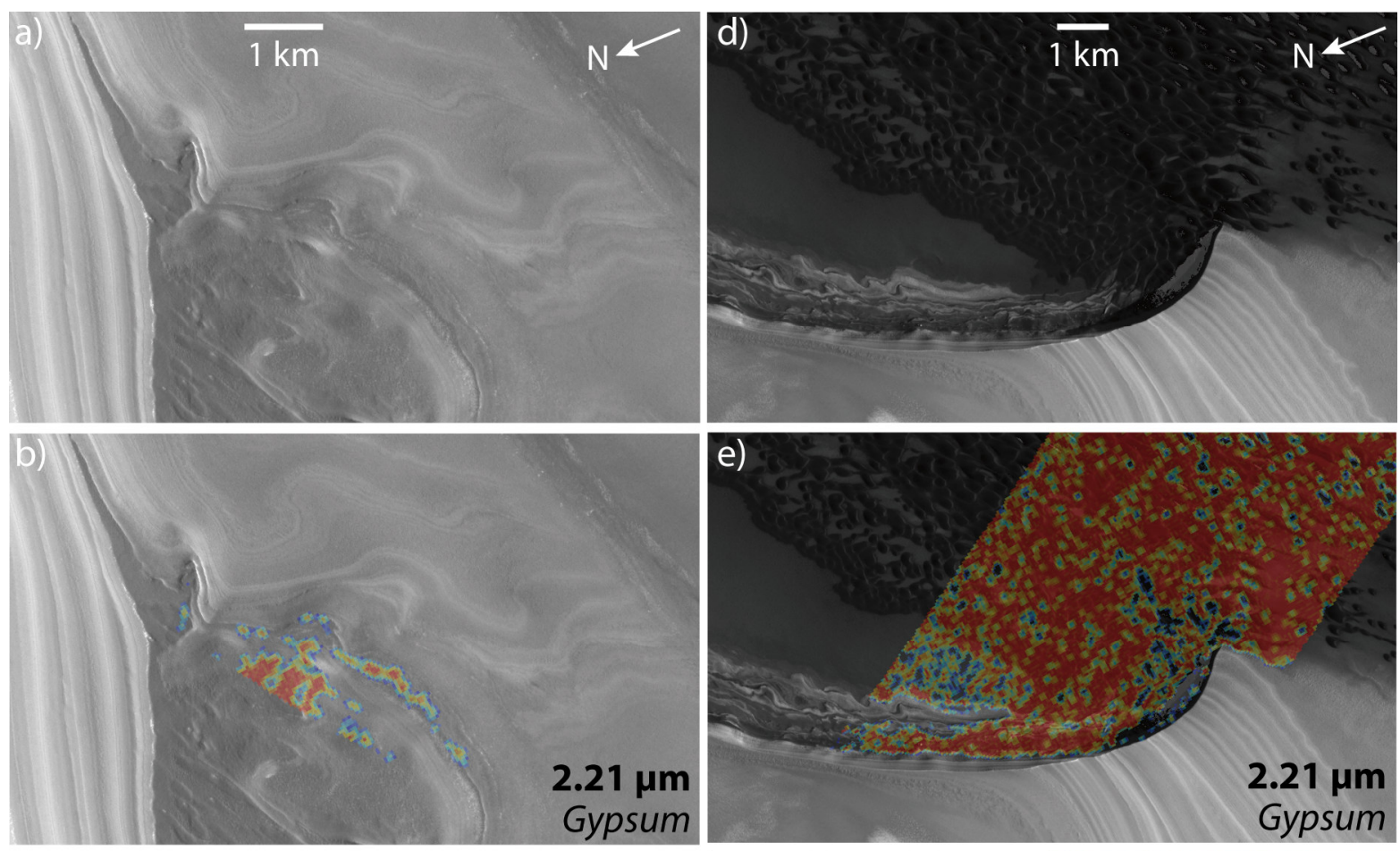

1141
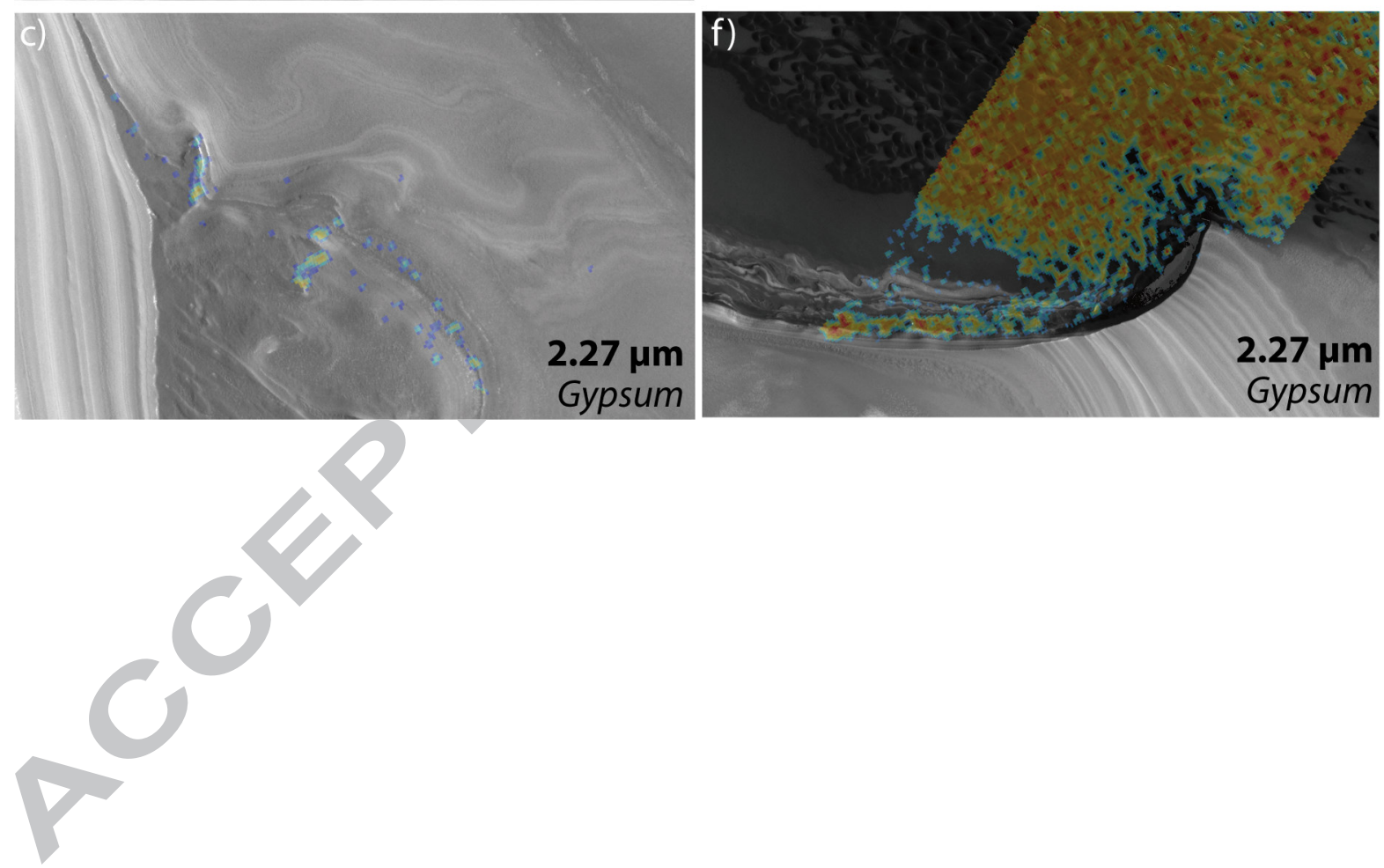
DUNES

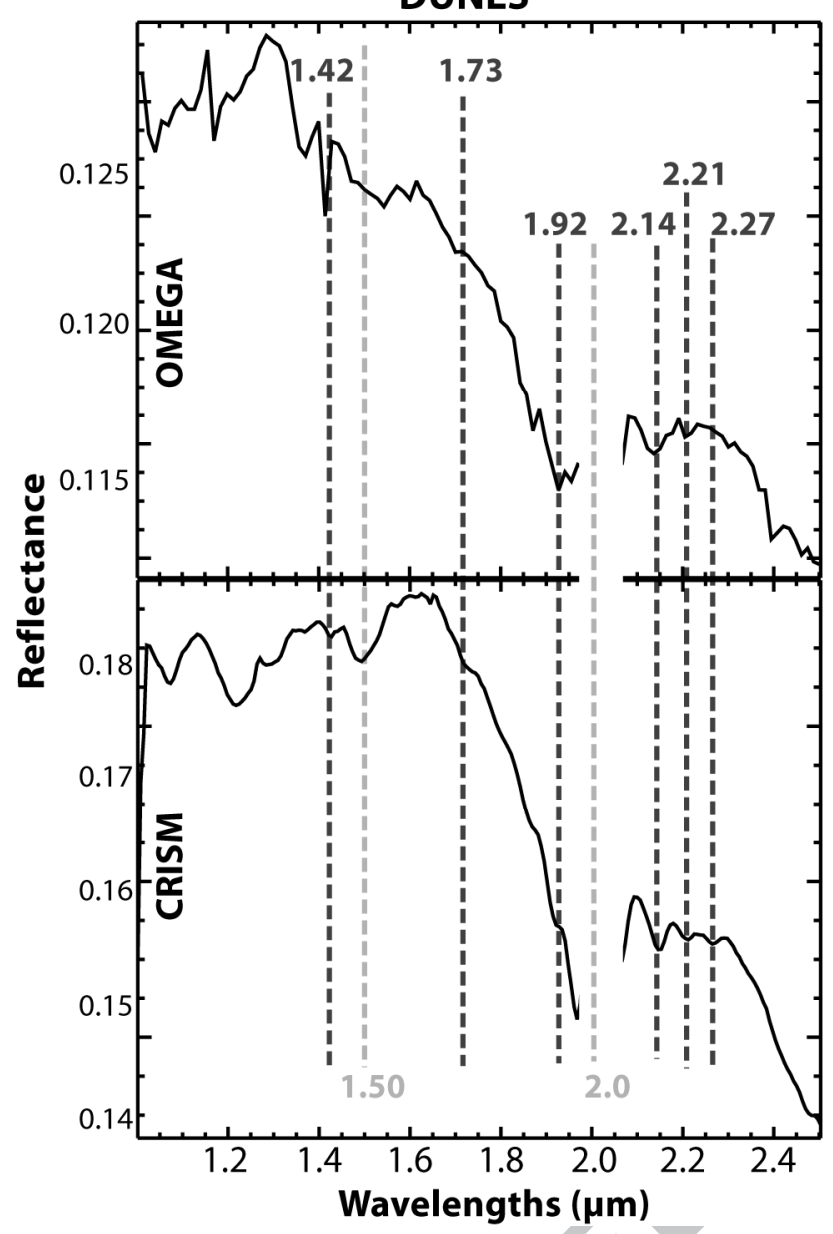

SUBLIMATION TILL

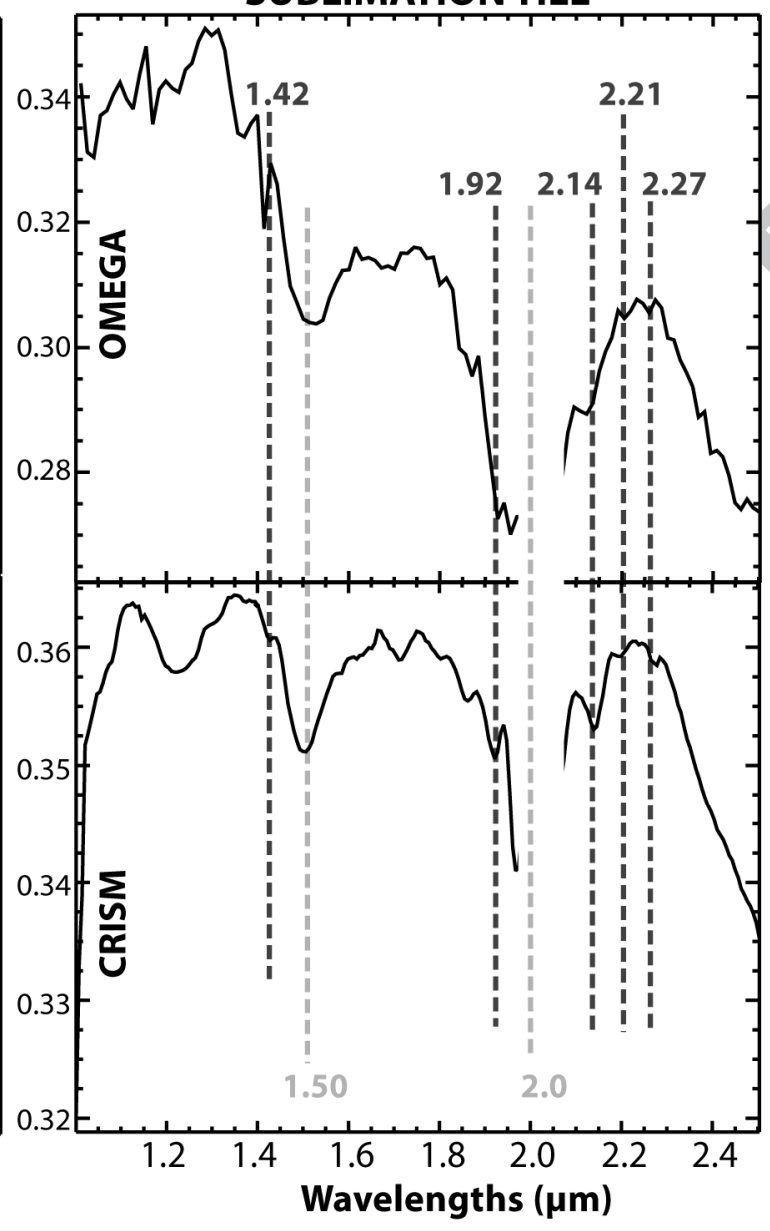



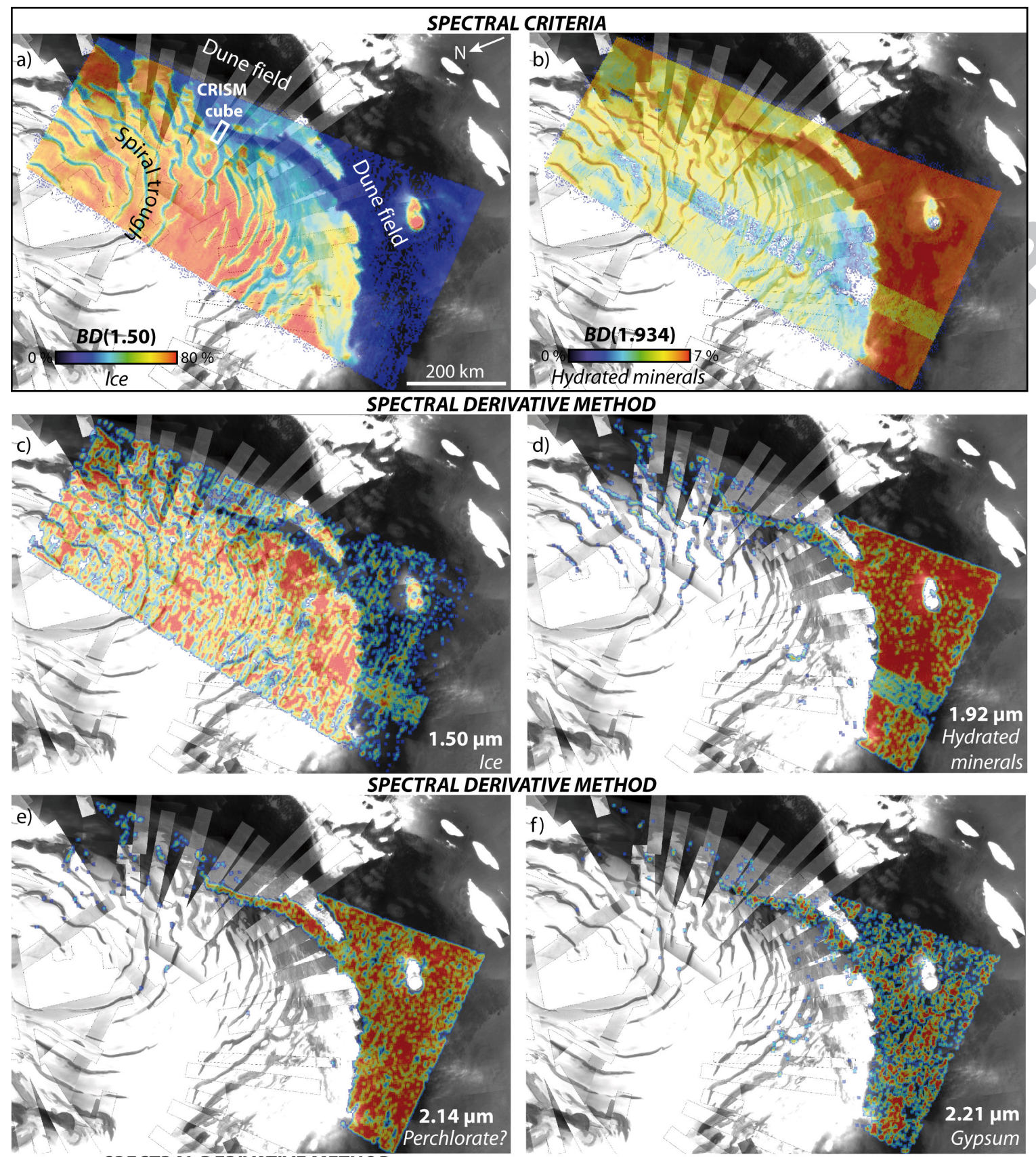

VATIVE METHOD

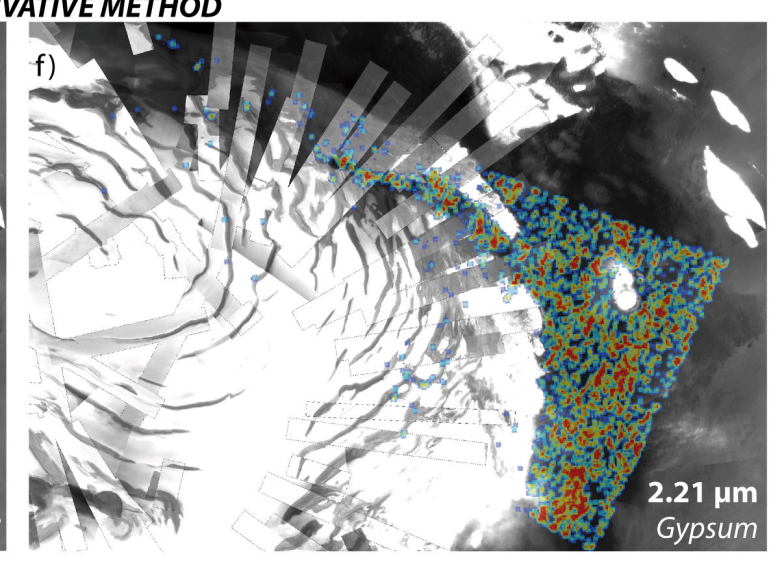
SPECTRAL DERIVATIVE METHOD
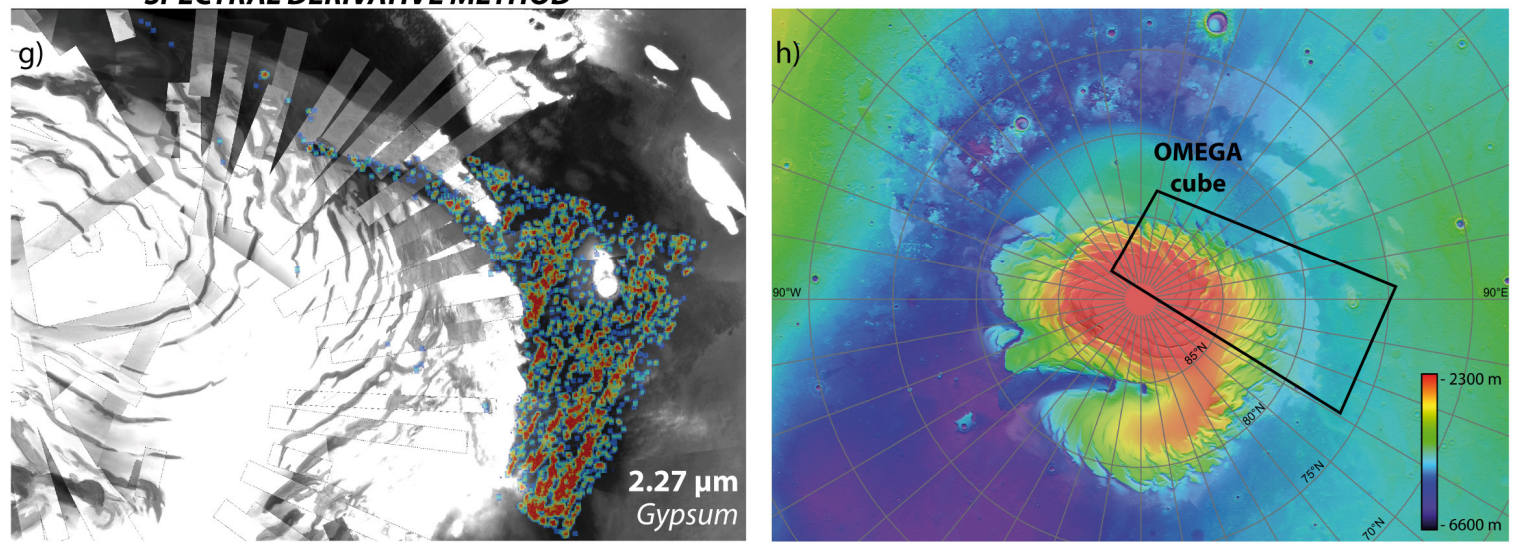
a) Accumulation of ice layers containing gypsum crystals

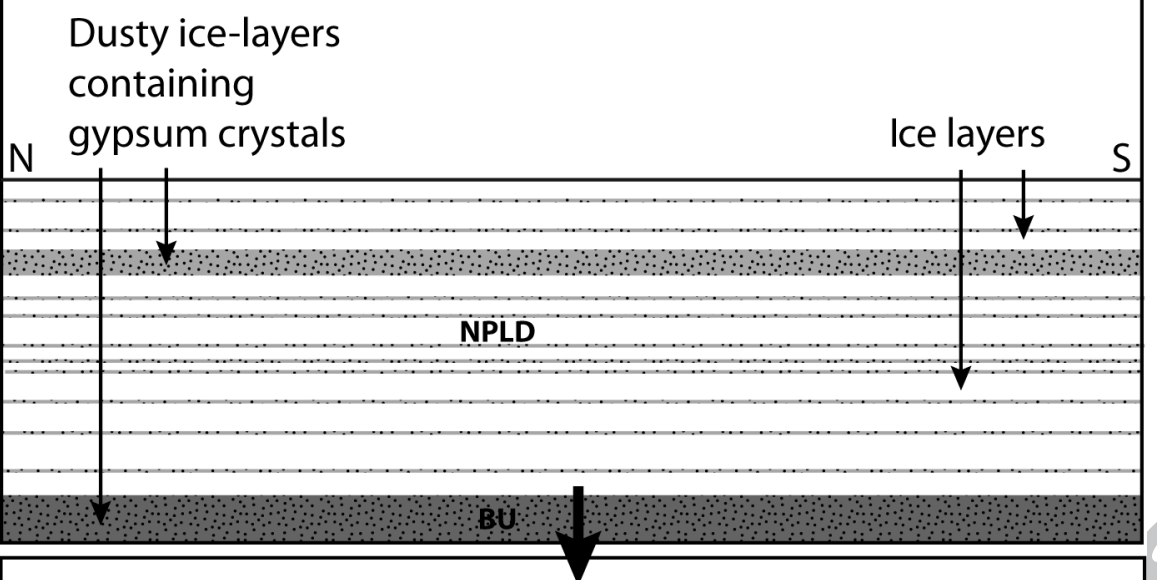

b) Ablation of ice and formation of gypsum-bearing sublimation till<smiles></smiles><smiles>[C+]1=C[C+]=CC1</smiles><smiles>C1=[Ge]=[Ge][Ge]1</smiles>

Ice sublimation

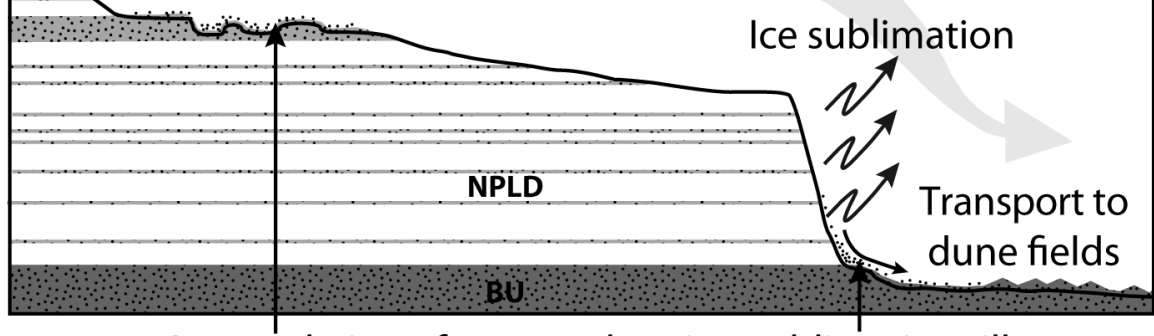

Accumulation of gypsum bearing sublimation till 